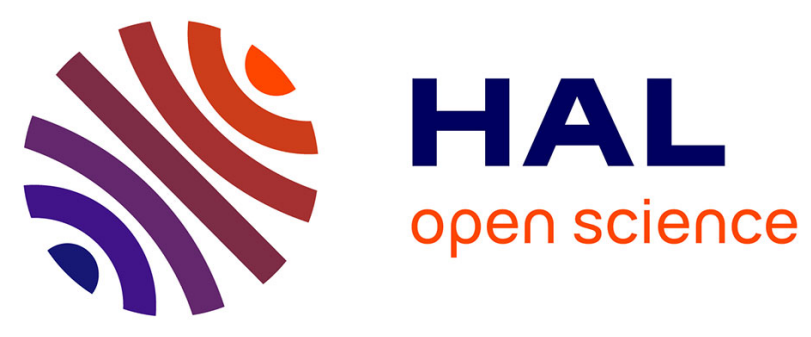

\title{
Postcranial anatomy of the extinct terrestrial sloth Simomylodon uccasamamensis (Xenarthra, Mylodontidae) from the Pliocene of the Bolivian Altiplano, and its evolutionary implications
}

Alberto Boscaini, Néstor Toledo, Bernardino Mamani Quispe, Rubén Andrade Flores, Marcos Fernández-monescillo, Laurent Marivaux, Pierre-Olivier Antoine, Philippe Münch, Timothy Gaudin, François Pujos

\section{- To cite this version:}

Alberto Boscaini, Néstor Toledo, Bernardino Mamani Quispe, Rubén Andrade Flores, Marcos Fernández-monescillo, et al.. Postcranial anatomy of the extinct terrestrial sloth Simomylodon uccasamamensis (Xenarthra, Mylodontidae) from the Pliocene of the Bolivian Altiplano, and its evolutionary implications. Papers in Palaeontology, 2021, 7 (3), pp.1557-1583. 10.1002/spp2.1353 . hal-03136053

\section{HAL Id: hal-03136053 \\ https://hal.umontpellier.fr/hal-03136053}

Submitted on 9 Feb 2021

HAL is a multi-disciplinary open access archive for the deposit and dissemination of scientific research documents, whether they are published or not. The documents may come from teaching and research institutions in France or abroad, or from public or private research centers.
L'archive ouverte pluridisciplinaire HAL, est destinée au dépôt et à la diffusion de documents scientifiques de niveau recherche, publiés ou non, émanant des établissements d'enseignement et de recherche français ou étrangers, des laboratoires publics ou privés. 


\title{
Palaeontology \\ The Palaeontological Association \\ Registered Charity No. 11683330
}

\begin{abstract}
POSTCRANIAL ANATOMY OF THE EXTINCT TERRESTRIAL SLOTH SIMOMYLODON UCCASAMAMENSIS (XENARTHRA: MYLODONTIDAE) FROM THE PLIOCENE OF THE BOLIVIAN ALTIPLANO AND ITS EVOLUTIONARY IMPLICATIONS
\end{abstract}

\begin{tabular}{|r|l|}
\hline Journal: & Palaeontology \\
\hline Manuscript ID & PALA-06-20-4813-OA.R1 \\
\hline Manuscript Type: & Original Article \\
\hline Author: & n/a \\
\hline Complete List of Authors: & $\begin{array}{l}\text { Boscaini, Alberto; Universidad Nacional de la Plata, } \\
\text { Toledo, Nestor; Museo de La Plata, División Paleontología de Vertebrados } \\
\text { Mamani Quispe, Bernardino; Museo Nacional de Historia Natural de } \\
\text { Bolivia } \\
\text { Andrade Flores, Rubén ; Museo Nacional de Historia Natural de Bolivia } \\
\text { Fernández-Monescillo, Marcos; Universidad Nacional de Córdoba Facultad } \\
\text { de Ciencias Exactas Físicas y Naturales } \\
\text { Marivaux, Laurent; Institut des sciences de II'evolution, Paleontology } \\
\text { Antoine, Pierre-Olivier; ISEM CCO64 } \\
\text { Münch, Philippe; Géosciences Montpellier, Université de Montpellier, } \\
\text { CNRS } \\
\text { Gaudin, Timothy; University of Tennessee at Chattanooga, Department } \\
\text { of Biological and Environmental Sciences } \\
\text { Pujos, François; Instituto Argentino de Nivología, Glaciología y Ciencias } \\
\text { Ambientales, CCT-CONICET-Mendoza }\end{array}$ \\
\hline Key words: & \begin{tabular}{l} 
anatomy, extinct sloth, evolution, Mylodontinae, postcranium, skeleton \\
\hline
\end{tabular} \\
\hline
\end{tabular}

\section{SCHOLARONE \\ Manuscripts}


POSTCRANIAL ANATOMY OF THE EXTINCT TERRESTRIAL SLOTH

SIMOMYLODON UCCASAMAMENSIS (XENARTHRA: MYLODONTIDAE)

\author{
FROM THE PLIOCENE OF THE BOLIVIAN ALTIPLANO AND ITS
}

\title{
EVOLUTIONARY IMPLICATIONS
}

\author{
by ALBERTO BOSCAINI ${ }^{1,2 *}$, NÉSTOR TOLEDO ${ }^{1}$, BERNARDINO MAMANI QUISPE ${ }^{3}$, \\ RUBÉN ANDRADE FLORES 3 , MARCOS FERNÁNDEZ-MONESCILLO ${ }^{4}$, LAURENT \\ MARIVAUX ${ }^{5}$, PIERRE-OLIVIER ANTOINE5 ${ }^{5}$ PHILIPPE MÜNCH ${ }^{6}$, TIMOTHY J. \\ GAUDIN $^{7}$ and FRANÇOIS PUJOS ${ }^{8}$
}

${ }^{1}$ CONICET, División Paleontología Vertebrados, Museo de La Plata, Unidades de Investigación Anexo Museo, FCNyM, Calle 60 y 122, 1900 La Plata, Argentina; e-mails: alberto.boscaini@gmail.com

(https://orcid.org/0000-0002-8666-9340); ntoledo@,fcnym.unlp.edu.ar (https://orcid.org/0000-0002-6833$\underline{3165)}$

${ }^{2}$ Current address: Instituto de Ecología, Genética y Evolución de Buenos Aires (IEGEBA - CONICET). DEGE, Facultad de Ciencias Exactas y Naturales, Universidad de Buenos Aires, Int. Guiraldes 2160, Buenos Aires, Argentina.

${ }^{3}$ Departamento de Paleontología, Museo Nacional de Historia Natural de Bolivia, Calle 26 s/n, Cota Cota, La Paz, Bolivia; e-mails: bmamaniq@hotmail.com; randradeflores@gmail.com

${ }^{4}$ Museo de Paleontología, Facultad de Ciencias Exactas, Físicas y Naturales, Universidad Nacional de Córdoba, Vélez Sarsfield 249, X5000JJC, Córdoba, Argentina; e-mail: mfernandezmonescillo@gmail.com (https://orcid.org/0000-0002-0698-1909)

${ }^{5}$ Laboratoire de Paléontologie, Institut des Sciences de l'Évolution de Montpellier (ISE-M, UMR 5554, CNRS/UM/IRD/EPHE), c.c. 64, Université de Montpellier (UM), Place Eugène Bataillon, 34095 Montpellier Cedex 05, France ; e-mails: laurent.marivaux@umontpellier.fr (https://orcid.org/0000-0002-2882-0874); pierreolivier.antoine@umontpellier.fr (https://orcid.org/0000-0001-9122-1818)

${ }^{6}$ Géosciences Montpellier (UMR 5243, CNRS/UM/Université des Antilles), c.c. 060, Université de Montpellier (UM), Place Eugène Bataillon, 34095 Montpellier Cedex 05, France ; e-mail : philippe.munch@umontpellier.fr (https://orcid.org/0000-0003-4616-8039) 


\author{
${ }^{7}$ Department of Biology, Geology, and Environmental Science, University of Tennessee at Chattanooga, 615 \\ McCallie Ave, Chattanooga TN, 37403-2598, USA; e-mail: Timothy-Gaudin@utc.edu (https://orcid.org/0000- \\ $\underline{0003-0392-5001)}$ \\ ${ }^{8}$ Instituto Argentino de Nivología, Glaciología y Ciencias Ambientales (IANIGLA), CCT-CONICET-Mendoza, \\ Avda. Ruiz Leal s/n, Parque Gral. San Martín, 5500 Mendoza, Argentina; e-mail: fpujos@mendoza- \\ conicet.gob.ar (https://orcid.org/0000-0002-6267-3927) \\ *Corresponding author
}

\begin{abstract}
Extinct terrestrial sloths are common elements of the late Cenozoic South American fossil record. Among them, Mylodontinae species were particularly abundant in the Americas throughout the Pleistocene epoch, and their anatomy is relatively well known. In contrast, less information is available from the Neogene record and particularly from localities at low latitudes, with an additional and considerable bias in favor of craniodental rather than postcranial remains. In this contribution, we provide comparative descriptions of several postcranial bony elements ascribed to Simomylodon uccasamamensis, a moderatesized extinct mylodontine from the Andean Altiplano. This species was particularly abundant during latest Miocene-late Pliocene times in the high altitudes of the Andean Cordillera, and so far represents the best known mylodontine from the Neogene of South America. Its anatomy is compared with that of several extinct terrestrial sloths, with the aim of using the observed morphologies to elucidate taxonomy, phylogeny, and locomotion. From a morphofunctional perspective, the postcranium of $S$. uccasamamensis is consistent with that of a terrestrial graviportal quadruped, with moderate climbing and digging capabilities.
\end{abstract}

Key words: anatomy, extinct sloth, evolution, Mylodontinae, postcranium, skeleton, 
EXTANT SLOTHS (Folivora) are only represented by two genera, Bradypus and Choloepus, restricted to tropical American rainforests, whereas their extinct taxonomic richness was conspicuously greater (e.g., McKenna \& Bell 1977; Gaudin 2004; Gaudin \& Croft 2015). This clade, together with anteaters (Vermilingua) and armadillos, pampatheres, and glyptodonts (Cingulata), comprise Xenarthra, one of the four major lineages of placental mammals (Meredith et al. 2011; O’Leary et al. 2013).

Sloths comprise a significant component of late Cenozoic South American fossil mammalian assemblages, with more than 90 recorded genera (McKenna \& Bell 1997; Pujos et al. 2017). Mylodontidae constitutes one of the major folivoran subdivisions, ranging chronologically from the late Oligocene to the Pleistocene-Holocene interval, and geographically to cover North and South America almost entirely (e.g., Pujos \& De Iuliis 2007; McDonald \& De Iuliis 2008; Shockey \& Anaya 2011; Gaudin \& Croft 2015; Boscaini et al. 2019a). Morphology-based phylogenies did not seem to support relationships between modern sloths and extinct mylondontids (e.g., Gaudin 2004; Varela et al. 2018). However, recent molecular phylogenetic analyses suggest that the living two-toed sloth Choloepus could be an extant member of Mylodontidae (Delsuc et al. 2019; Presslee et al. 2019).

Among Mylodontidae, Mylodontini and Lestodontini are sister clades that independently radiated across South and North America between the late Miocene and the late Pleistocene (Boscaini et al. 2019a). Both groups comprised moderately- to large-sized and even gigantic quadrupedal herbivores, the majority of which exhibited grazing adaptions (Pujos et al. 2012). In general, Pleistocene Mylodontidae are well known, but less information is available for Paleogene and Neogene members. This is especially true for Mylodontini, in which the earlier and smaller representatives are far less well known that the larger and more recent forms. 
The Neogene Mylodontini species Simomylodon uccasamamensis is an endemic taxon from late Miocene-late Pliocene deposits of the Andean Altiplano (Saint-André et al. 2010; Boscaini et al. 2019b; Quiñones et al. 2019). This species was erected by Saint-André et al. (2010), and new abundant remains from the Bolivian Altiplano were subsequently studied by Boscaini et al. $(2019 b, c)$. In these works, many craniodental elements were considered, allowing for an assessment of both interspecific variation among Neogene mylodontines (Boscaini et al. 2019b) and the intraspecific variation within S. uccasamamensis, possibly related to sexual dimorphism (Boscaini et al. 2019c). Abundant fossils of this species were recovered in Neogene fossil-bearing Bolivian sites, from the departments of La Paz, Oruro and Potosí (Fig. 1; Boscaini et al. 2019b). More precisely, fossil remains come from the latest Miocene/early Pliocene of Choquecota, the early Pliocene of Casira, Inchasi and PomataAyte, and the late Pliocene of Ayo Ayo-Viscachani (for further information on these localities, see Boscaini et al. 2019b). Recently, Quiñones et al. (2019) reported new remains of S. uccasamamensis from Casira, thereby extending the geographic range of this taxon to the Argentine side of the Casira Basin. Interestingly, the chronological distribution of $S$. uccasamamensis is bracketed between two major faunal turnover events which took place in the Bolivian highlands, i.e., the Miocene-Pliocene and the Pliocene-Pleistocene transitions (Hoffstetter 1986; Marshall et al. 1983; Marshall \& Sempéré 1991).

In the Neogene fossil record of early South American mylodontines, postcranial elements are relatively rare. Indeed, the appendicular anatomy of the South American mylodontines Glossotheridium chapadmalense (southeastern Argentina, early Pliocene; Kraglievich 1925) and Pleurolestodon acutidens (Argentina, late Miocene; Rovereto 1914), is represented only by a single humerus and a single astragalus, respectively. A greater number of postcranial elements, including several autopodial elements, are known for the North American 
Paramylodon garbanii (='Glossotherium' chapadmalense; Mexico and USA, Pliocene; Robertson 1976; Montellano-Ballesteros \& Carranza-Castañeda 1986).

The new abundant material of S. uccasamamensis from Casira, Inchasi, Pomata-Ayte and Ayo Ayo-Viscachani now allows for an almost complete characterization of the appendicular anatomy of this extinct sloth, thereby making this taxon one of the best known Neogene mylodontines from South America. We provide here a comprehensive analysis of the postcranial anatomy of S. uccasamamensis, and particularly its appendicular elements. The phylogenetic signal and functional implications of many features are also discussed. The characterization of the postcranial anatomy of S. uccasamamensis is of great interest to further our understanding of the evolutionary changes that occurred in Mylodontidae. It provides new information for morphology-based phylogenetic analyses and paleobiological reconstructions of extinct sloths.

\section{MATERIAL AND METHODS}

\section{Fossil sample}

The new postcranial elements for Simomylodon uccasamamensis described here were recovered from several localities on the Bolivian Altiplano (Fig. 1; Boscaini et al. 2019b). These fossils are deposited in the MNHN-Bol, MNHN, and UF collections (see abbreviations below). The complete list of fossil materials and their provenance is reported in Supporting Information, Appendix S1. These postcranial elements were compared with their homologues in several mylodontid and non-mylodontid taxa (see Supporting Information, Appendix S2). Whenever possible, comparisons were made by first-hand examination of the specimens, but we sometimes relied on high-quality photographs or bibliographic sources. Recent studies on 
appendicular anatomy of extinct sloths were consulted as sources of information for muscle attachments (see Toledo et al. 2013, 2015; Amson et al. 2015a, b; and references therein).

Regarding the axial postcranium, only a small portion of the pelvis and isolated/fragmented vertebrae and ribs have been discovered, thereby impeding a reliable assessment of the axial morphology. For this reason, the comparative description is mainly centered around the elements of the forelimb and hind limb. For these bones, the presence of multiple specimens of the same element, in some cases, also allowed observations regarding their intraspecific variation (Boscaini et al. 2019c). Measurements for all specimens were taken with a digital caliper to the nearest $0.1 \mathrm{~mm}$ (Supporting Information, Appendix S3).

\section{Abbreviations}

Anatomical abbreviations. mtc, metacarpal; mtt, metatarsal.

Institutional abbreviations. AMNH, American Museum of Natural History, New York, USA; AMU-CURS, Colección de Paleontología de Vertebrados de la Alcaldía de Urumaco, Urumaco, Venezuela; CIAAP, Centro de Investigaciones Antropológicas, Arqueológicas y Paleontológicas, Coro, Venezuela; F:AM, Frick collection, American Museum of Natural History, New York, USA; FMNH, Field Museum of Natural History, Chicago, USA; IVIC, Instituto Venezolano de Investigaciones Científicas, Caracas, Venezuela; JUY-P, Museo de Geología, Mineralogía y Paleontología, Instituto de Geología y Minería, Universidad Nacional de Jujuy, San Salvador de Jujuy, Argentina; MACN, Museo Argentino de Ciencias Naturales "Bernardino Rivadavia," Buenos Aires, Argentina; MCN, Museo de Ciencias Naturales, Caracas, Venezuela; MLP, Museo de La Plata, La Plata, Argentina; MNHN, Muséum national d'Histoire naturelle, Paris, France; MNHN-Bol, Museo Nacional de 
Historia Natural de Bolivia, La Paz, Bolivia; ROM, Royal Ontario Museum, Toronto, Canada; UCMP, Museum of Paleontology, University of California, Berkeley, USA; UF, University of Florida, Florida Museum of Natural History (FLMNH), Gainesville, USA; USNM, National Museum of Natural History, Smithsonian Institution, Washington, D.C., USA; YPM-PU, Princeton University collection housed at Peabody Museum, Yale University, New Haven, USA.

\title{
SYSTEMATIC PALAEONTOLOGY
}

\author{
XENARTHRA Cope, 1889 \\ PILOSA Flower, 1883 \\ FOLIVORA Delsuc et al., 2001 \\ MYLODONTIDAE Gill, 1872 \\ MYLODONTINAE Gill, 1872 \\ Simomylodon Saint-André et al., 2010 \\ Simomylodon uccasamamensis Saint-André et al., 2010 \\ (Figs 2-14; Supporting Information, Appendices S1, S3)
}

Synonyms

Glossotheriscum dalenzae Saint-André, 1994: 174-183, fig. 18, pl. 13.

Simotherium uccasamamense Saint-André, 1994: 184-228, figs. 19-20, pls. 14-20.

Glossotheridium chapadmalense: Anaya \& MacFadden, 1995: 94-98, figs. 3-5, tab. 1, nec Kraglievich 1925.

Pleurolestodon dalenzae Saint-André et al. 2010: 261-269, figs. 2-4, tab. 1.

Mylodontinae indet. Anaya \& MacFadden, 1995: 98-99, figs 6-7.

Mylodontidae gen. indet. sp. indet. Quiñones et al. 2019: 8, fig. 6, tab. 2. 
Mylodontinae gen. indet. sp. indet. Quiñones et al. 2019: 8-9, fig. 7, tab. 2.

Simomylodon cf. S. uccasamamensis Quiñones et al. 2019: 10-13, figs 9-10, tab. 3.

\section{Referred material}

See Supporting Information, Appendix S1

\section{Measurements}

See Supporting Information, Appendix S3

\section{Revised postcranial diagnosis}

[The following diagnosis of S. uccasamamensis is based on postcranial traits, and is intended to complement the craniodental diagnosis reported in Boscaini et al. (2019b: p. 465)]. In S. uccasamamensis, the lateral margin of the supinator crest of the humerus exhibits a convex profile, and the lateral and medial humeral epicondyles are equally expanded in anterior view. The radius displays a marked convexity of its anterior margin in lateral view. In the manus, the mediolateral width of the trapezoid is greater than its dorsopalmar length, and the magnum can be either free or fused with the third metacarpal. The tibia is mediolaterally narrow in relation to total length (ratios ranging from 0.18 and 0.30 ), possessing two large grooves for the passage of tendons on the posteromedial margin of the distal epiphysis. In the pes, the calcaneum displays a well-developed sustentacular process. The astragalus exhibits a well-marked sulcus tali, a flat surface of the discoid process in lateral view, and a moderately obtuse discoid-odontoid angle (ranging between $90^{\circ}$ and $115^{\circ}$ ) observable in either anterior or posterior views. The third metatarsal is dorsopalmarly thin in relation to its total length (ratios ranging from 0.23 and 0.31 ), and bears a distinct facet for 
the second metatarsal proximally. The fifth metatarsal has an arched ventral profile in lateral view. Small, subspherical osteoderms are present.

\section{RESULTS}

\section{Comparative description}

Scapula. The anatomy of the scapula of S. uccasamamensis was previously unknown (Saint-André et al. 2010). The available scapula, MNHN-Bol V 3718 (Fig. 2), is associated with a skull (Boscaini et al. 2019b: fig. 8), and therefore its assignment to $S$. uccasamamensis is clear. The scapular morphology of mylodontid sloths is very conservative, so that the main differences are essentially size-related. The scapula of Simomylodon is very similar in shape not only to the homologous element in Glossotherium, Mylodon and Paramylodon, but also in the lestodontines (Owen 1842; Stock 1925; Webb 1989). Scapulae of Catonyx and Scelidotherium appear slightly more elongated anteroposteriorly, due to the more acute angle between the vertebral and posterior borders (McDonald 1987).

In lateral view, the scapula of $S$. uccasamamensis exhibits a strong scapular spine, which divides the anterior supraspinous fossa from the posterior infraspinous fossa, and served as an attachment area for a well-developed spinodeltoideus muscle, as well as part of the trapezius complex. The supraspinous and infraspinous fossae are large and roughly equal in size; the former housed the supraspinatus muscle and the latter the infraspinatus muscle. The secondary spine is confined to the posterior border, delimiting a very reduced post-scapular fossa (Fig. 2), which housed both the triceps brachii caput longus and teres major muscles. The scapular spine extends ventrally into the acromion process, which extends anteriorly to fuse with the coracoid process, forming the acromiocoracoid arch typical of sloths (e.g., 
Engelmann 1985; Rose \& Emry 1993; McDonald 2003). This arch bears the articulation for the clavicle, which appears elliptical in outline (Fig. 2B). In ventral view, the glenoid cavity is pyriform, with its anteriormost end narrower mediolaterally than its posterior end. All these features are invariably present in Mylodontidae (e.g., Stock 1925; McDonald 1987). In ventral view, the long axes of the glenoid fossa and the clavicular facet form an acute angle in Simomylodon (Fig. 2B), as they do in other mylodontines (e.g., Glossotherium MACN Pv 14066 and Paramylodon FMNH P14723) and in scelidotheriines (e.g., Catonyx FMNH P14238 and Scelidotherium FMNH P14274). In contrast, this angle is roughly orthogonal in Lestodon (MACN Pv 14648). Unfortunately, due to lack of preservation, this feature has not been observed in Thinobadistes and Bolivartherium, so that it remains unclear whether the morphology in Lestodon is typical for lestodontines in general.

In medial view, the scapula of $S$. uccasamamensis MNHN-Bol V 3718 shows a pronounced posterior ridge of the subscapular fossa, forming a wide and triangular area for the teres minor muscle (and probably also the triceps brachii caput longus and the teres major; Fig. 2C). This feature is common in all known Mylodontinae, whereas this fossa is reduced in size and more posteriorly oriented in Scelidotheriinae.

Humerus. Seventeen humeral fragments assigned to S. uccasamamensis are available for study (Supporting Information, Appendix S1). However, the only complete specimen is the right humerus MNHN-Bol V 13367, depicted in Figure 3. The humerus of $S$. uccasamamensis is robust, with its distal end broader mediolaterally than its proximal end in anterior view (Fig. 3). In proximal view (Fig. 3A), the humeral head is subspherical in shape, and adjacent anteromedially to the lesser tuberosity (where the subscapularis inserted) and anterolaterally to the greater tuberosity (where both the supra- and infraspinatus muscles inserted). The latter is more protruded externally than the former in proximal view (Fig. 3A), 
a widespread feature in Mylodontidae (Boscaini et al. 2019a: char. 304). An exception is represented by Nematherium (YPM-PU 15374 and FMNH P13131), in which the opposite condition is present. The latter conformation is also observed in Hapalops and Bradypus, thereby suggesting that this condition is primitive for sloths (Boscaini et al. 2019a: char. 304).

The greater tuberosity continues ventrally into the deltopectoral shelf, which shows a rugose surface for attachment of the muscles in the pectoralis and deltoid complex (Fig. 3B). The deltopectoral shelf faces anterolaterally and has an oblique distal margin, a plesiomorphic feature of Mylodontinae (Boscaini et al. 2019a: chars 301-302). In contrast, in Nematherium, Scelidotherium and Catonyx, the deltopectoral crest shows a derived morphology. In these taxa, the deltopectoral crest has a more horizontal distal margin and faces more anteriorly, overlapping the ascending entepicondylar ridge in anterior view (Boscaini et al. 2019a: chars 301-302).

In anterior view, the lateral epicondyle is expanded laterally, and delimited by a laterally convex supinator crest (Fig. 3B), where the brachioradialis, supinator and many extensor muscles of the manus attached. The supinator crest curves medially to reunite with the humeral shaft in close proximity to the end of the deltopectoral shelf, as observed in Thinobadistes, Pseudoprepotherium and Nematherium (Boscaini et al. 2019a: char. 303). In the other Mylodontidae, the profile of the supinator crest is less regular and its most distal portion is proximodistally vertical. As is typical for mylodontids, the medial epicondyle, which served as an attachment site for many manual flexor muscles, bears a distinct proximal process (Boscaini et al. 2019a: char. 307). Furthermore, as in all Mylodontinae, the entepicondylar foramen is lacking (Fig. 3B; McDonald \& De Iuliis 2008; Boscaini et al. 2019a: char. 306). The medial and lateral epicondyles extend transversely to approximately the same degree (Fig. 3B), a condition that is also observed in Thinobadistes (Webb 1989) 
and Pseudoprepotherium (Hirschfeld 1985). In Nematherium, Catonyx and Scelidotherium, the medial epicondyle is wider than the lateral epicondyle, whereas the opposite is true in the remainder of the Mylodontinae (Boscaini et al. 2019a: char. 308).

In distal view (Fig. 3C), both epicondyles are directed posteriorly, as is also observed in G. robustum, P. harlani, M. darwinii and G. chapadmalensis. In Pseudoprepotherium, the medial epicondyle is directed medially, whereas in Lestodon it is directed anteriorly. In Thinobadistes, the humerus varies in this feature: both epicondyles are either directed posteriorly or mediolaterally in distal view (Boscaini et al. 2019a: chars 311-312). In the same view, the capitulum and the trochlea of Simomylodon have approximately the same anteroposterior depth (Fig. 3C), a widespread feature among mylodontids, with the exception of Scelidotherium and Catonyx, in which the trochlea is consistently deeper anteroposteriorly than the capitulum. However, the trochlea of S. uccasamamensis appears transversely wider than the capitulum (Fig. 3C), in this way more closely resembling G. chapadmalensis and $P$. harlani, rather than M. darwinii and G. robustum among Mylodontini. In the latter taxa, the mediolateral widths of the capitulum and trochlea are equivalent (Boscaini et al. 2019a: chars 309-310).

Radius. Features on the radius of S. uccasamamensis can be observed in eight specimens, two of which are complete: MNHN.F.AYO180 (Saint-André et al. 2010: fig. 11) and MNHN-Bol V 3375 (Fig. 4). The general morphology of the radius of S. uccasamamensis is more similar to that of Pseudoprepotherium (Hirschfeld 1985) and the lestodontines (Webb 1989), rather than the remaining Mylodontinae. In fact, the ratio between the anteroposterior radial depth, measured at midshaft, and the proximodistal length reaches its maximum values among mylodontids in the genera Pseudoprepotherium, Thinobadistes, Lestodon and Simomylodon (Boscaini et al. 2019a: char. 314). This is due to the presence of a well- 
developed pronator ridge (for attachment of the pronator teres muscle) that makes the anterior border of the radius anteriorly convex in lateral view (Fig. 4B). In contrast, the posterior border is straight in lateral view (Fig. 4B). This combination of features is observed in Simomylodon, Pseudoprepotherium, Thinobadistes and Lestodon (Hirschfeld 1985; Webb 1989). In other Pleistocene Mylodontinae, like Mylodon, Glossotherium and Paramylodon, the radius has a more straight and stocky structure, lacking a well-developed pronator crest (Owen 1842; Stock 1925; McAfee 2016; Cartelle et al. 2019). In contrast, Nematherium, Scelidotherium and Catonyx possess an anteriorly concave posterior border that, together with the anteriorly convex anterior border, give a sinuous aspect to the radius in lateral view. This latter morphology results in a bend of the shaft that is typical of scelidotheriines (McDonald 1987; Boscaini et al. 2019a: chars 316-317). The radial or bicipital tuberosity of Simomylodon is conspicuous, proximodistally elongated, and marked by a slightly concave terminal surface (Fig. 4C-D).

In Simomylodon, the shape of the radial head is piriform, with straight lateral and medial sides, as in the majority of Mylodontidae. In contrast, the radial head is generally more rounded in Nematherium, Scelidotherium, Catonyx, Thinobadistes (Boscaini et al. 2019a: char. 315) and G. wegneri (De Iuliis et al. in press). However, the proportions of the distal articulation of the radius do not vary conspicuously among mylodontids (Boscaini et al. 2019a: char. 320). The distal radius is marked by a low ridge separating the facets for the scaphoid and the lunar in MNHN.F.AYO180 (Saint-André et al. 2010), but this ridge is absent in MNHN-Bol V 3375 (Fig. 4F). The former condition is widespread in Mylodontidae (e.g., Rautenberg 1906; Haro et al. 2017), whereas the latter condition is typical of Pseudoprepotherium and the scelidotheriines (Hirschfeld 1985; McDonald 1987). A similar intraspecific variation of the latter feature has also been observed in G. robustum (Rautenberg 1906; Pitana 2011). 
Ulna. An almost complete ulna, lacking part of the olecranon and the distal epiphysis, is available for description: MNHN-Bol V 3717 (Fig. 5; Supporting Information, Appendix S1). The ulna was previously unknown for S. uccasamamensis (Saint-André et al. 2010) and its recovery in association with a complete cranium (Boscaini et al. 2019b: fig. 7) allows a definitive assignment to this species. The ulna is relatively short proximodistally and deep anteroposteriorly, as in other Mylodontinae, with the exception of Pseudoprepotherium (Hirschfeld 1985). In the latter taxon, but also in Nematherium, Scelidotherium and Catonyx, the ulna is narrower anteroposteriorly and more elongated proximodistally (Boscaini et al. 2019a: char. 322). The olecranon meets the posterior edge of the ulna at a wide angle, comparable to the condition in all Mylodontinae with the exception of Thinobadistes segnis (Webb 1989) and Glossotherium wegneri (De Iuliis et al. in press). In these latter taxa, the proximal and posterior borders of the ulna meet at an almost orthogonal angle (Webb 1989; De Iuliis et al. in press), a feature also observed in Scelidotherium and Catonyx (McDonald 1987; Boscaini et al. 2019a: char 323).

In anterior view, the trochlear notch of Simomylodon is marked by well-defined lateral and medial facets, which both culminate at the same height at the level of the anconeal process (Fig. 4A), as in Paramylodon harlani and P. garbanii. The lateral portion is more proximally extended than the medial portion in G. robustum, M. darwinii and L.armatus, whereas the opposite condition is observed in Thinobadistes, Nematherium, Catonyx and Scelidotherium. The radial notch is also well defined, and its area is relatively wider in Simomylodon (in comparison with the trochlear notch) than in Mylodon, Glossotherium and Paramylodon (Boscaini et al. 2019a: chars 324-325).

In posterior view (Fig. 5C), the width of the ulna decreases from proximal to distal, as observed in all Mylodontinae with the exception of Pseudoprepotherium. In the latter, but 
also in Nematherium, Scelidotherium and Catonyx, the ulna is columnar in posterior view, with a uniform transverse width along its entire length (Boscaini et al. 2019a: char. 326). These four latter genera also differ from other mylodontids in the inclination of the distal articular facet for the cuneiform. In these taxa, the long axis of the facet is oblique, so that in lateral view its anterior margin is more proximal than its posterior edge (McDonald 1987). However, in all the other Mylodontidae, the distal articular facet is at a right angle to the long axis of the shaft in lateral view (Boscaini et al. 2019a: char. 328). Unfortunately, this latter feature cannot be observed in S. uccasamamensis because the distal ulnar epiphysis is missing (Fig. 5).

Manus. The manus of S. uccasamamensis has the typical mylodontid conformation, with five metacarpals and ungual phalanges on the first three digits only. This pattern is present in the manus of almost all known mylodontid sloths, with the exception of Scelidotherium, in which the ungual is also missing on the first digit (McDonald 1987).

Several elements of the manus of $S$. uccasamamensis are available and preserved threedimensionally (Figs 6-8), allowing an extensive characterization of its morphology. Two of these elements, the scaphoid and trapezium, were described by Saint-André et al. (2010), and subsequently glued into an assembled manus, rendering it impossible to observe all of their features in detail. For this reason, photos of these two elements (Fig. 6) were taken directly from Saint-André et al. (2010).

The scaphoid of Simomylodon (Fig. 6A-B) is similar in shape to that of other mylodontids. It bears an elongated medial process that supports the facet for the co-ossified trapezium and first metacarpal (carpal-metacarpal complex). The latter facet is separated from the facet for the trapezoid as in all Mylodontinae, and in contrast with Scelidotheriinae, in which the two facets are contiguous (McDonald 1987). In Nematherium, Scelidotherium 
and Catonyx, the medial process is relatively less elongated, and the scaphoid generally shows a blockier aspect than in other Mylodontidae. Accordingly, the former three genera exhibit a higher ratio between the minimum and maximum diameters (i.e., mediolateral width and proximodistal length) of the scaphoid (Boscaini et al. 2019a: char. 331). The facets for the trapezoid and magnum are separate and almost equal in size in MNHN.F.AYO180, the only available scaphoid of S. uccasamamensis (Fig. 6A-B; Saint-André et al. 2010). However, in larger samples from other mylodontines, such as Thinobadistes and Paramylodon (AMNH, FMNH, UF collections; Stock 1925), the arrangement of these facets is highly variable.

The morphology of the lunar is extremely conservative in Mylodontidae (McDonald 1987). In the mylodontid lunars observed in the present study (see Supporting Information, Appendices S1, S2), no reliable difference in proportions has been detected. The lunarscaphoid contact is separated into two distinct facets in MNHN.F.AYO111 (Fig. 6C), with the proximal one clearly larger than the distal one. In MNHN.F.AYO180, the distal facet is absent (Saint-André et al. 2010). The shape of the facets of the lunar-scaphoid contact, and their mutual interconnection, are also variable in Paramylodon, Thinobadistes and several scelidotheriines (McDonald 1987). On the proximal aspect of the lunar, the facet for the radius is rounded and forms a wide convex surface (Fig. 6D), whereas on the distal aspect, three contiguous facets can be differentiated (Fig. 6E). The latter are for connection with the magnum medially, unciform centrally, and cuneiform laterally (Fig. 6E).

The general shape of the mylodontid cuneiform is that of a cube with a flat proximal facet for the ulna, a more complex distal facet for the unciform, and smaller facets for the lunar and pisiform (McDonald 1987). However, the cuneiform differs significantly in some proportions among Mylodontidae (Haro et al. 2016; Boscaini et al. 2019a: chars 333-335). In Simomylodon (Fig. 6F-H), together with all other mylodontines, the ratio of its dorsopalmar 
depth and mediolateral width is quite uniform. This ratio is intermediate between those registered for Nematherium (which shows the lowest, and hence a more mediolaterally elongated cuneiform) and Catonyx, Scelidotherium and Thinobadistes (which show the highest, and hence a more dorsopalmarly elongated cuneiform). The ratio between the proximodistal length and mediolateral width of the cuneiform only differentiates Nematherium from the rest of the mylodontids. However, the ratio between the proximodistal and dorsopalmar widths differentiates between Mylodontinae and Scelidotheriinae, with the former having the higher ratios (cuneiform longer than deep). In the latter feature, Thinobadistes and Paramylodon show a certain degree of variation (Boscaini et al. 2019a: chars 333-335). In the cuneiform of scelidotheriines, the lunar facet is positioned on a process (McDonald 1987), which results in marked separation between the cuneiform and the lunar. In contrast, this process is absent in Mylodontinae, so that the facet is adjacent to the medial surface of the cuneiform (Boscaini et al. 2019a: char. 332). The latter configuration is also observed in Simomylodon (Fig. 6G-H).

The trapezoid of S. uccasamamensis (Fig. 6I-K) contacts the scaphoid, magnum and mtc2, as in all mylodontid sloths. For this reason, the arrangement of the facets is similar in all taxa considered in the present study. However, in S. uccasamamensis the mediolateral width of the trapezoid is greater than its dorsopalmar length, a feature already noted by SaintAndré et al. (2010) and previously observed only in P. garbanii (Montellano-Ballesteros \& Carranza-Castañeda 1986). The opposite condition is found in other Mylodontidae, including S. leptocephalum, T. segnis, G. robustum, P. harlani and M. darwinii (Supporting Information, Appendix S2).

No isolated magnum is so far known for S. uccasamamensis. The magnum is fused with mtc3 in two of five specimens. This fusion is present in MNHN.F.AYO179 (Fig. 7I-M) and MNHN.F.AYO180, whereas it is absent in the three isolated mtc3s: MNHN.F.VIZ27 (Fig. 
7F-H), MNHN.F.VIZ5 and MNHN-Bol V 12927. The fused specimens do not belong to the same individual (both of them are left hand elements) and do not exhibit bone regrowth on either side of the fused elements. This suggests that this connection is not related with any pathology, but represents instead a peculiar trait of Simomylodon, that sometimes occurs in the available sample. This condition is unknown in any other mylodontid. Even if the two elements are fused, a transverse nutritive foramen is present at the level of their connection, thereby allowing visual identification of the plane of separation (Fig. 7K, M). In this way, it is possible to observe that the magnum has no visible connection with mtc2 in dorsal view. The connection between the magnum and mtc 2 is confined to a single facet on the palmar edge, a typical feature of Mylodontinae (McDonald 1987). On the contrary, an extensive contact between these two elements is visible on the dorsal side of the manus in scelidotheriine sloths (Haro et al. 2016; Boscaini et al. 2019a: char. 339).

In proximal view, the unciform of $S$. uccasamamensis displays a strong process for the lunar, and a relatively short lateral platform for the cuneiform (Fig. 6L). The proximodistal width of that bone exceeds its transverse width, a condition also observed in M. darwinii, $G$. robustum, $P$. harlani and some specimens of $T$. segnis. The opposite pattern is observed in all the other mylodontids (Boscaini et al. 2019a: char. 336). In distal view, the unciform displays well-developed facets for metacarpals three, four and five (Fig. 6N). The former is located medially and divided into two articular surfaces. Immediately lateral to these two facets is the facet for mtc4, which is undivided, and abuts an even further laterally positioned and welldeveloped facet for mtc5 (Fig. $6 \mathrm{~N}$ ). The extensive unciform/mtc5 contact is common in Mylodontinae. However, a significant reduction of the unciform-fifth metacarpal facet is observed in Catonyx, and the contact is completely absent in Scelidotherium, where mtc5 articulates only with mtc4 (McDonald 1987; Boscaini et al. 2019a: char. 342). 
A pisiform (Fig. 6O-P) and two manual sesamoids (Fig. 6Q-T) of S. uccasamamensis were also recovered. The pisiform shows a globose shape and a rugose external surface (Fig. 6O-P), resembling that of G. robustum, P. garbanii, P. harlani and T. segnis (Owen 1842; Stock 1925; Robertson 1976; Webb 1989), whereas the element is more dorsopalmarly flattened in M. darwinii (Haro et al. 2016). The pisiform bears a single, flat and ovoid facet for the cuneiform (Fig. 6P).

Two distal sesamoids of mtc4 of S. uccasamamensis were also identified on the basis of their resemblance to their homologues in M. darwinii and P. harlani (Stock 1925; Haro et al. 2016). The medial mtc4 distal sesamoid (Fig. 6Q-R) is consistently larger in size than the lateral one (Fig. $6 \mathrm{~S}-\mathrm{T})$. The sesamoids appear as tiny, proximodistally elongated bony elements, with a rugose external surface and a single concave facet for mtc4 (Fig. 6Q-T).

The trapezium and mtc1 are fused in S. uccasamamensis (Fig. 7A-B), forming the carpalmetacarpal complex, a feature observed in most sloths (McDonald 1977; Amson et al. 2015; Boscaini et al. 2019a: char 337). The two elements are separate in Octodontotherium grande (MNHN.F.DES231), and in some specimens of Paramylodon harlani (Stock 1925). The carpal-metacarpal complex possesses two separate proximal facets: a larger one for articulation with the scaphoid and a smaller, lateral one for articulation with mtc2. As in the majority of Mylodontinae, there is no facet for the trapezoid on the carpal-metacarpal complex (McDonald 1987), but a small contact has been reported for M. darwinii (Haro et al. 2016). Distally, the carpal-metacarpal complex of S. uccasamamensis has a subspherical facet for the proximal phalanx of the first digit (Fig. 7A-B).

The second metacarpal of S. uccasamamensis (Fig. 7C-E) is relatively elongated and narrow mediolaterally. In proximal view, mtc2 bears a large articular surface for the trapezoid and a smaller one for the magnum. The latter, as noted above, is confined to the 
palmar side of the bone (Fig. 7C-E). The facet for the carpal-metacarpal complex on the lateral side is reduced, whereas the facet for $\mathrm{mtc} 3$ is wide and medially concave (Fig. 7C-D).

As described above, mtc3 of S. uccasamamensis can be found either isolated (Fig. 7F-H) or fused with the magnum (Fig. 7I-M). In the isolated condition, mtc3 appears relatively long proximodistally and thin mediolaterally, especially near the midshaft, resembling that of $O$. grande, Ps. confusum, Pa. garbanii, M. darwinii and M. ibseni in this respect, whereas in the other mylodontids, this element is relatively shorter and thicker (Cartelle 1980; Boscaini et al. 2019a: char. 341). The articular surface for mtc2 is convex (Fig. 7), and the shafts of the two metacarpals (mtc2 and mtc3) are separated by a moderately developed proximomedial process on mtc3. This feature in S. uccasamamensis is similar to the condition observed in lestodontines. It is intermediate between the morphology of Nematherium, Catonyx, Scelidotherium, Pseudoprepotherium and Octodontotherium (in which the process is shorter and the two metacarpals are closer together) and that of Mylodon, Paramylodon and Glossotherium (in which mtc2 and mtc3 show an even greater separation due to the presence of a longer process; Boscaini et al. 2019a: char. 340).

Only a proximal fragment of mtc4 of S. uccasamamensis is available (Fig. $7 \mathrm{~N}-\mathrm{P})$. In proximal view, the contacts with mtc3 and the unciform are contiguous, with the latter more extended dorsopalmarly than the former (Fig. $7 \mathrm{~N}$ ). On the lateral side, the facet for mtc 5 is flat and triangular in outline (Fig. 7P).

The fifth metacarpal of S. uccasamamensis (Fig. 7Q-S) is similar in shape to that of other Mylodontinae such as Thinobadistes, Paramylodon, Mylodon and Glossotherium (Owen 1842; Stock 1925; Webb 1989; Haro et al. 2016; McAfee 2016; Cartelle et al. 2019). This element is more gracile in scelidotheriines (McDonald 1987), and shorter and wider in Lestodon (MACN Pv 10760). In Simomylodon, the proximal portion of mtc5 shows two large adjacent facets for mtc4 and the unciform, respectively (Fig. 7Q-R). This conformation is 
observed in virtually all mylodontids with the exception of Scelidotherium, in which mtc5 only contacts mtc4 proximally (McDonald 1987). In Simomylodon, there is no evidence for an articulation with the cuneiform, as also observed in Catonyx (McDonald 1987), Lestodon (MACN Pv 10760) and Thinobadistes (Webb 1989). However, in Thinobadistes, an extremely reduced surface articulation is visible in some specimens (e.g., AMNH F:AM 102850). A small articulation between the cuneiform and mtc5 is present in M.darwinii (Haro et al. 2016), P. harlani (Stock 1925), P. garbanii (Montellano-Ballesteros \& CarranzaCastañeda 1986), G. robustum (Owen 1842) and G. phoenesis (Cartelle et al. 2019). As in all mylodontids, the distal end of mtc5 bears a small ovoid facet for the proximal (and probably only) phalanx. This latter element, usually rudimentary, is not currently available for

\section{Simomylodon.}

The proximal and intermediate phalanges of MNHN-Bol V 3313 (Fig. 8A-G) are very similar in shape to those of G. robustum and P. harlani (Owen 1842; Stock 1925), and thus likely belonged to the right third digit of S. uccasamamensis. Also, the three ungual phalanges of MNHN.F.AYO180 (Fig. 8H-P) are likely those of the first three digits of the left hand, based on their relative size. The ungual phalanges are covered proximally by bony sheaths, which show different stages of completeness, and are pierced by paired subungual foramina on their ventral surface (Fig. $8 \mathrm{H}-\mathrm{P}$ ). The osseous ungual cores are almost circular in cross-section, as in G. robustum and P. harlani (Owen 1842; Stock 1925). As in P. harlani (Stock 1925), two symmetrical concavities mark the ventral side of the core, and are deeper in the ungual phalanx of the second digit (Fig. 8K-M) than the third digit (Fig. 8N-P). As already noted, the presence of three clawed digits on the manus is a widespread mylodontid feature, although not present in Scelidotherium, which lacks an ungual on digit 1 (Winge 1915; McDonald 1987; Boscaini et al. 2019a: char. 343). 
Femur. Twenty femora/femoral fragments of S. uccasamamensis have been recovered, but only eight of them are relatively complete (Supporting Information, Appendix S1). Of these eight, five appear larger and more robust than the other three, an indication of sizebased sexual dimorphism as suggested by Boscaini et al. (2019c). However, the following descriptions and comparisons are valid for all the available femoral specimens.

The femur of S. uccasamamensis (Fig. 9) is similar in shape to that of the other Mylodontinae. The ratio between the mediolateral width at midshaft and proximodistal length is similar among mylodontines, but is consistently higher in the scelidotheriines (McDonald 1987; Boscaini et al. 2019a: char. 344). As in all mylodontines, the femur of Simomylodon is narrower distally than proximally in anterior view. In Simomylodon, the ratio between maximum femoral condylar width and femoral length is similar to that of most other Mylodontinae. This ratio is intermediate between the lowest value recorded for mylodontids, that of Pseudoprepotherium, Urumacotherium and Mirandabradys, and the highest value recorded, that of the scelidotheriines (Boscaini et al. 2019a: char. 345). Also, the ratio between the intertrochanteric width and the proximodistal length of the femur is consistent among mylodontids, with the scelidotheriines representing an exception, exhibiting the highest observed values (Boscaini et al. 2019a: char. 347). Similarly, the ratio between the anteroposterior depth and the mediolateral width measured at the femoral midshaft is similar in all mylodontids, with Catonyx and Scelidotherium showing the lowest values (Boscaini et al. 2019a: char. 348).

In Simomylodon, the greater trochanter is broad mediolaterally and deep anteroposteriorly, but is not elongated proximodistally (Fig. 9). In fact, it does not reach the proximal level of the femoral head in anterior view, a feature shared with many mylodontids. Basal megatherioid sloths like Hapalops are characterized by a nearly equivalent proximal extension of the femoral head and the greater trochanter, but this morphology is only 
observed among mylodontids in Pseudoprepotherium (Boscaini et al. 2019a: char. 350). The greater trochanter of S. uccasamamensis shows a rugose area for attachment of gluteal (gluteus minimus and medius) and femoral abductor (pyriformis) muscles. A vertical crest on the anterior surface of the proximal femur marks the separation of these entheses (i.e., muscle attachments, sensu Mariotti et al. 2007) from the origins of a powerful vastus complex (knee extensors).

The femoral neck is moderately extended proximomedially in Simomylodon (Fig. 9). In anterior view, the neck gradually decreases in width from its base to its contact with the edge of the femoral head. This same morphology is observed in Lestodon, Mylodon, Glossotherium and Paramylodon (Boscaini et al. 2019a: chars 351-352). In contrast, Thinobadistes shows a more distinct sulcus surrounding the articular surface of the femoral head, whereas Catonyx and Scelidotherium lack a conspicuous femoral neck (McDonald 1987; Webb 1989).

In posterior view (Fig. 9D), S. uccasamamensis exhibits a well-developed intertrochanteric fossa and lacks the intertrochanteric ridge connecting the trochanters. Among Mylodontidae, a real intertrochanteric ridge connecting the trochanters is present only in Baraguatherium takumara (Rincón et al. 2016), resembling in this regard the Santacrucian megatherioid Hapalops (Boscaini et al. 2019a: char. 349).

The femur of Simomylodon possesses a third trochanter that is elongated proximodistally, but is not as laterally prominent as that in Baraguatherium and Pseudoprepotherium (Boscaini et al. 2019a: char. 353). This results in a relatively straight, vertical lateral edge of the femoral shaft, which is the most common condition in mylodontids, as represented for instance by Glossotherium and Paramylodon (Fig. 9; Owen 1842; Stock 1925; Cartelle et al. 2019). As in most ground sloths, this area acted as an extended insertion enthesis for the 
powerful gluteus maximus muscle and the iliotibial tract (= tensor fasciae latae), both flexors and abductors of the femur.

In distal view (Fig. 9F), the femur of Simomylodon does not present remarkable differences from other Mylodontinae such as Glossotherium, Lestodon, Paramylodon, Pseudoprepotherium and Thinobadistes (Owen 1842; Stock 1925; Robertson 1976; Hirschfeld 1985; Webb 1989; Cartelle et al. 2019; Vargas-Peixoto et al. 2019). In all these taxa the larger medial tibial condyle and the smaller lateral tibial condyle are confluent with the patellar groove (Fig. 9F). In Simomylodon, the transverse width of the distal articular surface of the femur is greater, in relation to its anteroposterior depth, than that of Pseudoprepotherium and Thinobadistes, thus resembling the condition of Mylodontini such as Glossotherium and Paramylodon (Owen 1842; Stock 1925; Cartelle et al. 2019).

Tibia. The tibia of S. uccasamamensis is known from 16 specimens, 10 of which are relatively complete (Supporting Information, Appendix S1). As is the case with the femora, the complete tibiae vary in their general aspect: three of them are larger and more robust than the remaining ones (Boscaini et al. 2019c). However, the descriptions and comparisons of the tibiae of $S$. uccasamamensis are applicable to the entire sample.

The tibia of S. uccasamamensis (Fig. 10A-F) is similar, in its general aspect, to the homologous element in Mylodon, Glossotherium, and Paramylodon, but it also shares several features in common with Lestodon and Thinobadistes (e.g., Owen 1842; Stock 1925; Webb 1989; Cartelle et al. 2019; Vargas-Peixoto et al. 2019). In lateral and medial views (Fig. 10A, C), the tibia of S. uccasamamensis is straight, a common mylodontid feature (Boscaini et al. 2019a: char. 355). However, the diaphysis is fairly uniform in anteroposterior depth, as in Mylodon, Glossotherium and Paramylodon (Owen 1842; Stock 1925; Cartelle et al. 2019), whereas the diaphysis decreases in anteroposterior depth from the proximal to the distal end 
in lestodontines (Webb 1989; Vargas-Peixoto et al. 2019). The latter morphology is also observed in Pseudoprepotherium (Hirschfeld 1985), Octodontotherium (FMNH P13517) and in scelidotheriines (McDonald 1987).

The ratio between the anteroposterior depth of the proximal epiphysis and the total tibial length is greater than 0.35 in Simomylodon, as in several mylodontids, with the exceptions of Pseudoprepotherium, Octodontotherium, Mirandabradys and Urumacotherium, in which the ratio is lower (Boscaini et al. 2019a: char. 357). At the distal end, the ratio between anteroposterior depth and the total tibial length is high in Simomylodon, Mylodon, Paramylodon and Glossotherium (greater than 0.74). Lower values (between 0.60 and 0.74 ) are consistently observed in Scelidotherium, Catonyx, Pseudoprepotherium and Octodontotherium. The values for Lestodon and Thinobadistes fall between these ranges (Boscaini et al. 2019a: char. 358). The ratio between the maximum mediolateral width of the proximal epiphysis and the total tibial length is always less than 0.6 in Simomylodon, as in Catonyx, Pseudoprepotherium, Octodontotherium and Thinobadistes, whereas it is higher than 0.6 in Mylodon, Glossotherium and Paramylodon. This feature is variable in Lestodon and Scelidotherium (Boscaini et al. 2019a: char. 359).

In proximal view (Fig. 10E), the medial and lateral tibial condyles of Simomylodon are markedly unequal in size, with the former much larger than the latter, a typical feature of terrestrial sloths (Boscaini et al. 2019a: chars 360-361). Both tibial condyles are concave, but the lateral is nearly flat. As in Pseudoprepotherium, Octodontotherium and the scelidotheriines, the tibia of Simomylodon lacks any trace of a groove anterior to the lateral condyle. In all other mylodontids a groove is present (Boscaini et al. 2019a: char. 362); it faces laterally and probably accommodated the tendon of origin of the extensor digitorum longus muscle (Evans \& de Lahunta 2013). The tibial tuberosity is, as in most ground sloths, 
wide, shallow and massive, thereby indicating a powerful and wide insertion tendon for both the quadriceps femoris and tensor fasciae latae muscles.

The medial intercondylar eminence is not particularly evident in mylodontid sloths, but it is moderately developed in Octodontotherium, Pseudoprepotherium and Mirandabradys, resembling the basal megatherioid Hapalops in this regard (Boscaini et al. 2019a: char. 363).

In medial, posterior and distal views (Fig. 10C, D, F), two deep grooves for the tendons of the ankle extensor and digital flexor muscles are present on the postero-medial aspects of the distal tibia of $S$. uccasamamensis. These grooves are separated by a strong bony crest. The presence of these two well-separated grooves is also observed in Pseudoprepotherium, Thinobadistes and Lestodon. In Octodontotherium, the scelidotheriines, as well as in the megalonychid and nothrotheriid sloths, three distinct grooves are present (Stock 1925; McDonald 1987; Amson et al. 2015b). In nothrotheriids, these grooves accommodated (from anterior to posterior), the tendons for the tibialis posterior, flexor digitorum longus and flexor hallucis longus muscles, respectively (McDonald 1987; Amson et al. 2015b). In contrast, in Mylodon, Glossotherium and Paramylodon this area bears a single groove, which probably accommodated all three tendons. The condition of Simomylodon, Pseudoprepotherium and the lestodontines therefore appears to be intermediate between the other two configurations (Boscaini et al. 2019a: char. 365). Given that the posterior groove is larger than the anterior one in Simomylodon (Fig. 10C), the tendons for the flexor digitorum longus and flexor hallucis longus muscles were probably housed together in this groove, whereas the tendon for the tibialis posterior muscle likely occupied the anterior groove.

In distal view (Fig. 10F), the facet for the astragalus dominates the articular surface of the distal tibia. As in all sloths, it is composed of two concave surfaces, one subspherical for articulation with the odontoid process of the astragalus and the other nearly flat for articulation with the discoid process. The distal fibular facet is located in the posteromedial 
corner of the distal tibia, a position that is typical in Mylodontinae, with the exception of Pseudoprepotherium and Octodontotherium. In these two latter genera, as in the scelidotheriines (McDonald 1987), the distal tibial facet for the fibula is longer anteroposteriorly (Boscaini et al. 2019a: char. 364).

Patella, fibula and cyamella. The patella is represented in S. uccasamamensis by two specimens: MNHN-Bol V 3300 (Saint-André et al. 2010: fig. 17) and MNHN-Bol V 12518 (Fig. 10G-H). In anterior and posterior views, this bone is triangular in shape, and very similar to that of Glossotherium and Paramylodon (Owen 1842; Stock 1925). However, the patella of Lestodon and Thinobadistes is proximodistally longer, with a more pronounced ventral process (Webb 1989). In posterior view, the articular surface with the femur is transversely convex in the vicinity of its midpoint, but becomes medially and laterally concave, as it does in all mylodontids. In S. uccasamamensis, these latter areas appear equal in proximodistal extent in MNHN-Bol V 3300 (Saint-André et al. 2010: fig. 17), whereas they are more asymmetrical in MNHN-Bol V 12518 (Fig. 10H), with the medial facet elongated distally. Intraspecific variation in the shape of the patellar articular surface has been observed in specimens of Lestodon and Thinobadistes (Supporting Information, Appendix S2).

Six fibulae of S. uccasamamensis (Fig. 10I-L) are available (Supporting Information, Appendix S1). The fibula is conservative in its morphology among mylodontids (McDonald 1987). The ratio between the proximodistal length of the distal articular surface and the total length of the fibula is, for example, similar in all mylodontids (Boscaini et al. 2019a: char. 366). This bone is mediolaterally narrow and anteroposteriorly broad as in all Mylodontinae, in contrast to the condition in the scelidotheriines, in which it is more rounded in cross section (McDonald 1987). Proximally and medially, the fibula carries a flat, anteroposteriorly 
elongate facet for the tibia and, more posteriorly, a smaller and more convex facet for the cyamella.

In Mylodontidae, the presence of a cyamella (or fabella, or cyamo-fabella) has been reported for Scelidotherium (Burmeister 1881) and Mylodon (Roth 1899). In other taxa, such as Catonyx, Scelidotherium, Paramylodon, Pseudoprepotherium and Thinobadistes, its presence was inferred by the presence of articular surfaces on the proximal epiphyses of either the tibia, the fibula or both (Stock 1925; Hirschfeld 1985; McDonald 1987; Webb 1989). In S. uccasamamensis, both right and left cyamellae are available in MNHN-Bol V 12518 (Fig. 10M-N, 11). The cyamella is roughly spherical and, on its medial side, bears three contiguous but discrete facets (Fig. 10N). These are (from proximal to distal) for articulations with the femur, tibia and fibula, respectively. The facet for the tibia is the largest of the three (Fig. 10N). In proximal view, the femoral facet on the cyamella forms a continuous articular surface with the lateral condyle of the tibia for the articulation with the femur (Fig. 11C).

Pes. Several tarsal and metatarsal bones of S. uccasamamensis are available for description (Supporting Information, Appendix S1), but elements unequivocally attributable to the pedal phalanges are so far lacking.

Only a single complete calcaneum of S. uccasamamensis, MNHN-Bol V 8541, has been recovered (Fig. 12A-D). The posterior portion of the calcaneum corresponds to the tuber calcis (entheses for gastrocnemius, soleus, and plantaris muscles), which contacted the ground. This area is enlarged anteroposteriorly and mediolaterally, forming a triangular surface that is typical of Mylodontinae (Fig. 12A-C). Only Pseudoprepotherium exhibits a tuber calcis in which the anteroposterior length is not markedly enlarged (Hirschfeld 1985; Boscaini et al. 2019a: char. 374). However, the tuber calcis of S. uccasamamensis resembles 
that of Pseudoprepotherium, the lestodontines and the scelidotheriines, in lacking the strong mediolateral expansion observed on calcanei of G. robustum and P. harlani (Owen 1842; Stock 1925; Boscaini et al. 2019a: char. 373). As in all mylodontids, the tuber calcis of $S$. uccasamamensis is connected with the anterior articular portion by a neck region that is constricted dorsoventrally and mediolaterally (Fig. 12A-C). This neck in S. uccasamamensis is clearly shorter than that of scelidotheriines, which also lack a tendinous groove on the lateral and ventral sides (Fig. 12B-C). This groove probably housed the tendons of the peroneus longus and peroneus brevis muscles (McDonald 1987). Directly anterior to this groove, the articular portion of the calcaneum contacts the astragalus (Fig. 12E-H) and the cuboid (Fig. 13D-G). The calcanear-astragalar joint is divided into separate ectal and sustentacular facets, the former larger than the latter (Fig. 12D). In S. uccasamamensis, the sustentacular facet is located on a distinct medial process (Fig. 12A-D), the sustentaculum. The facet faces anteriorly and slightly laterally as in most ground sloths. The sustentaculum is not present in Glossotherium and Paramylodon (Owen 1842; Stock 1925; Boscaini et al. 2019a: char. 375; Cartelle et al. 2019), where ectal and sustentacular facets are confluent, and no sulcus calcanei is evident. The ectal facet of $S$. uccasamamensis is anteroposteriorly elongated and saddle-shaped (anteroposteriorly convex and mediolaterally concave), whereas it is almost flat in Glossotherium and Paramylodon (Owen 1842; Stock 1925; Cartelle et al. 2019). The cuboid facet is adjacent to the sustentacular facet, but separated by a ridge as in Glossotherium and Paramylodon, whereas in Scelidotherium these facets are separated by a smooth depression as in the basal megatherioid Hapalops (FMNH P13123).

Nine astragali of S. uccasamamensis have been recovered (Supporting Information, Appendix S1). The general astragalar proportions in Simomylodon, quantified by the ratio between the proximodistal and anteroposterior lengths (between 0.8 and 1.0), are similar to those of most Mylodontinae. The lowest values $(<0.8)$ are obtained in the basal 
mylodontines Octodontotherium and Pseudoprepotherium, and the highest values $(>1.0)$ in the scelidotheriines Catonyx and Scelidotherium (Boscaini et al. 2019a: char. 367). In Simomylodon, the medial and lateral trochlear surfaces of the astragalus are modified, as in all mylodontid sloths, to form a raised and globose odontoid process, and a flat, horizontal and semicircular discoid facet (Fig. 12E, F, H). However, the angle formed by the odontoid process and the discoid facet, observed in either anterior or posterior views, is quite different among various mylodontids (Boscaini et al. 2019a: char. 368). The odontoid-discoid angle is markedly obtuse $\left(>115^{\circ}\right)$ in the scelidotheriines, as it is in the basal mylodontine $O$. grande and the Pliocene North American species $P$. garbanii. It is moderately obtuse $\left(>90^{\circ}\right.$ but $<$ $115^{\circ}$ ) in most Mylodontinae, including G. robustum, M. darwinii, Pa. harlani, Ps. confusum, Pl. acutidens and S. uccasamamensis. In contrast, this angle is orthogonal or acute $\left(\leq 90^{\circ}\right)$ in the lestodontines. In the mylodontid astragalus, the discoid facet surrounds the odontoid process both laterally and posteriorly. In lateral view, the facet has an anteroposterior curvature in Nematherium, Octodontotherium, as well as in the scelidotheriines and the lestodontines, whereas it is essentially flat in Glossotherium, Mylodon, Paramylodon, Pleurolestodon, Pseudoprepotherium and Simomylodon (Fig. 12H; Boscaini et al. 2019a: char. 369). As in all mylodontids, the astragalus of S. uccasamamensis exhibits a proximodistally elongated facet for the fibula, located at the anteriormost limit of the discoid facet, and visible in lateral view (Fig. 12H). The shape of this facet is quite variable intraspecifically in S. uccasamamensis, as also observed in the large samples of Paramylodon and Thinobadistes.

As stated above, the ectal and sustentacular facets of the calcaneum are separated in $S$. uccasamamensis. The same pattern is observed on the astragalus (Fig. 12G; Saint-André et al. 2010), in which the two facets are separated by a deep sulcus tali. Both sulci delimit the sinus tarsi, occupied by an interosseous ligament. The presence of a sulcus tali is considered 
plesiomorphic among sloths (McDonald 1987). In Glossotherium, Mylodon and Paramylodon, these two facets coalesce into a uniform surface for the articulation with the calcaneum (e.g., Gervais 1873; Kraglievich 1926; McDonald 1987; Webb 1989). The plesiomorphic condition is found not only in Simomylodon, but also in Nematherium, Octodontotherium, Pseudoprepotherium, Pleurolestodon, as well as all lestodontines and scelidotheriines (Boscaini et al. 2019a: char. 370). In S. uccasamamensis, the sustentacular facet is confluent anteriorly with the facet for the cuboid (Fig. 12G), as is typical for Mylodontinae (McDonald 1987). The facet for the cuboid is anteriorly convex as in most mylodontids, whereas it is markedly concave in Nematherium (YPM-PU 15965) and in the scelidotheriines (McDonald 1987). The anteriormost portion of the astragalar head of $S$. uccasamamensis bears the articular surface for the navicular (Fig. 11E, F, H). This surface is flat to slightly concave in S. uccasamamensis (Fig. 12E, F, H), as observed in all mylodontines, whereas in the scelidotheriines this surface is more strongly concave (McDonald 1987). The intraspecific differences observed in S. uccasamamensis in the surface outline of this facet have been reported for other taxa, like P. harlani (Stock 1925), and directly observed in T. segnis (AB, unpub. data).

The navicular of S. uccasamamensis (Fig. 13A-C) has a typical mylodontine shape, being broader mediolaterally than deep dorsoventrally. The proximal surface is entirely occupied by a wide facet for the astragalus (Fig. 13B-C). On the distal surface, a wide elliptical facet for the ectocuneiform (and probably also for the mesocuneiform) is located along the ventralmost border (Fig. 13A, C). Adjacent and ventral to the latter facet, on the slender lateral surface of the bone, there is an anteroposteriorly narrow articulation for the cuboid (Fig. 13C).

The cuboid of S. uccasamamensis (Fig. 13D-G) is very similar to the homologous element in the large-bodied mylodontines such as G. robustum and P. harlani (Owen 1842; 
Stock 1925). In proximal view, there is a concave and almost circular facet for the astragalar head (Fig. 13E, G). The cuboid of S. uccasamamensis is delimited anteriorly by an anteroposteriorly narrow articulation for the navicular (Fig. 13E, G), and posteriorly by a dorsoventrally enlarged surface for the calcaneum (Fig. 13D). On the distal surface, there are two facets divided by an oblique ridge, for articulation with mtt5 posteriorly and mtt4 anteriorly (Fig. 13F). Anterodorsally to the latter, there is a smaller rectangular facet for mtt3 that faces anteromedially (Fig. 13G). The cuboid-mtt3 contact is absent in the scelidotheriines (McDonald 1987). Another difference among mylodontids is the presence/absence of the cuboid-ectocuneiform contact (Boscaini et al. 2019a: char. 376). This contact is extensive in the scelidotheriines and clearly visible in the articulated pes in lateral view, whereas it is very reduced in Pseudoprepotherium and the lestodontines, and absent in the other mylodontines such as G. robustum, P. harlani and S. uccasamamensis (Fig. 13D-I). According to Stock (1925), an extremely reduced cuboid-ectocuneiform facet is occasionally present in some specimens of P. harlani.

Therefore, the ectocuneiform of S. uccasamamensis (Fig. 13H-I) bears only two large facets: proximally, a concave surface for the navicular, and distally, a convex surface for $\mathrm{mtt} 3$. This bone is triangular in outline in proximal and distal views, with its longest border facing laterally. In this regard, it is very similar to the ectocuneiforms of G. robustum and $P$. harlani (Stock 1925).

The metatarsal series of $S$. uccasamamensis is known from two complete mtt3s, two incomplete $\mathrm{mtt} 4 \mathrm{~s}$ and two incomplete $\mathrm{mtt} 5 \mathrm{~s}$ (Supporting Information, Appendix S1).

The mtt3 of S. uccasamamensis (Fig. 13J-N) is smaller, in absolute terms, than in any other mylodontid mtt3, with the exception of P. garbanii (UF 10922), which possesses an $\mathrm{mtt} 3$ of similar size. The $\mathrm{mtt} 3$ of $S$. uccasamamensis is gracile, with a reduced dorsopalmar thickness of the shaft in relation to its total length (Boscaini et al. 2019a: char. 379), a 
plesiomorphic morphology that is only observed in O. grande among other mylodontid sloths. Another plesiomorphic feature on the mtt3 of S. uccasamamensis is the retention of a small articular facet for $\mathrm{mtt} 2$ (Fig. 13L-M). The mtt2-mtt3 articular surface is generally absent among Mylodontini (with the exception of P. garbanii; UF 10922), though it is commonly observed among Scelidotheriinae, basal Mylodontinae, and Lestodontini (Boscaini et al. 2109a: char. 378).

Only the proximal portion of $\mathrm{mtt} 4$ is available for observation (Fig. 13O-Q). It is smaller in size than the homologous element of G. robustum, P. harlani, T. segnis and L. armatus, resembling more closely that of $O$. grande and P. garbanii. A peculiarity of $\mathrm{mtt} 4$ in $S$. uccasamamensis is the reduced facet for mtt5 (Fig. 13Q; Saint-André et al. 2010). A similar conformation is observed only in $O$. grande among mylodontids, whereas in other members of this clade, this facet is more dorsopalmarly elongated.

In lateral view, the mtt5 of S. uccasamamensis (Fig. 13R-S) exhibits an arched profile, a feature that is plesiomorphic for mylodontids. The arched ventral border of mtt5 is a typical feature of Scelidotheriinae. Among Mylodontinae, it is recorded only in O. grande and some specimens of T. segnis (Boscaini et al. 2019a: char 382). In proximal view (Fig. 13R), the mtt5 of S. uccasamamensis possesses unequal articular facets for the cuboid and mtt4, with the former consistently larger than the latter.

\section{DISCUSSION}

The postcranial anatomy of Simomylodon uccasamamensis was partially described by Saint-André et al. (2010), but the present study includes many previously undescribed elements, and thus allows for a more complete investigation of the postcranial anatomy in this taxon. The new data allows for a reconsideration of previously described remains 
attributed to an "indeterminate Mylodontinae" by Anaya \& MacFadden (1995). These include a partial femur (MNHN-Bol V 3365) and an ungual phalanx (MNHN-Bol V 3355) from the late Pliocene Bolivian locality of Inchasi. These postcranial remains closely resemble in both shape and size the material of $S$. uccasamamensis described here, allowing us to assign these two fossil bones to this taxon.

In a similar way, several elements of uncertain attribution recovered from the Casira Basin and described by Quiñones et al. (2019) can be reassigned to S. uccasamamensis. These include the femoral and astragalar specimens JUY-P-0081, JUY-P-0082 and JUY-P0089 (Quiñones et al. 2019: figs 6-7, 10). In fact, these specimens are morphologically identical to those presented in this paper, and their dimensions (see Quiñones et al. 2019: tab. 2) fall well within the morphometric range of S. uccasamamensis (Supporting Information, Appendix S3). The same can also be said for the mandible JUY-P-0089, which Quiñones et al. (2019: fig. 9) recognized as similar to that of S. uccasamamensis. Considering this context, it is also plausible that the remaining mylodontine specimen described by Quiñones et al. (2019), a fragment of a juvenile skull (JUY-P-0173; Quiñones et al. 2019: fig. 8) can be ascribed to S. uccasamamensis. However, homologous comparative remains from a similar developmental stage have not been recovered in the material from the Bolivian Altiplano (Boscaini et al. 2019b), thereby impeding a definitive corroboration.

The large sample described in the present study, together with a previous analysis of craniodental remains (Boscaini et al. 2019b), permits now an almost total characterization of the skeletal anatomy of this species, making S. uccasamamensis the best known early member of Mylodontini. Overall, as noted by Saint-André et al. (2010), the postcranial anatomy of S. uccasamamensis closely resembles that of their larger and younger mylodontine relatives, such as the well-known Pleistocene taxa Glossotherium robustum and Paramylodon harlani (Owen 1842; Stock 1925). 
Indeed, S. uccasamamensis already displays some postcranial features that are recovered as synapomorphies of Mylodontini. These include the flat contour of the astragalar discoid process in lateral view (Boscaini et al. 2019a: char. 369) and the presence of osteoderms (Boscaini et al. 2019a: char. 383). In S. uccasamamensis, an agglomeration of small (around $4 \mathrm{~mm}$ in average diameter) osteoderms (Fig. 14) was found in association with the skull MNHN-Bol V 3726 from Casira (Boscaini et al. 2019b: fig. 6), and were probably derived from cranial/neck areas. An isolated, larger (around $17 \mathrm{~mm}$ diameter) osteoderm was found in association with an astragalus from the same locality, and tentatively attributed to $S$. uccasamamensis (Quiñones et al. 2019: fig. 10). Given the remarkable variation recognized in osteoderm shape and size in a single individual, even among dermal ossicles of the same anatomical region (Brambilla et al. 2019), it is plausible that both osteoderms belonged to $S$. uccasamamensis, thus serving to define the size range of these elements for this taxon. McDonald (2018) suggested that osteoderms may represent an independent acquisition in some sloth groups, rather than a retained plesiomorphic condition from the common ancestor of Xenarthra. This view was confirmed by recent reviews (Cartelle et al. 2019) and phylogenetic analyses (Boscaini et al. 2019a). Indeed, the presence of osteoderms was recovered as a synapomorphy of Mylodontini (Boscaini et al. 2019a) independently acquired by the Pleistocene scelidotheriine Valgipes bucklandi (Cartelle et al. 2019). The oldest prior record of sloth osteoderms was identified by Rovereto (1914) for Pleurolestodon, from the late Miocene of Argentina, but these fossils are currently missing from the MACN collection (Curator L. Chornogubsky, pers. comm.). However, isolated dermal ossicles were reported from coeval sediments of the same region by Nasif et al. (2008), thereby confirming that the earliest known appearance of the character for sloths is at least in the late Miocene. Even if their attribution is uncertain, they could plausibly be derived from P. acutidens. Osteoderms have not yet been reported in the Pliocene Mylodontini G. chapadmalense (Kraglievich 1925; 
McDonald 2018), but large numbers of osteoderms were recovered for the North American Pliocene species P. garbanii (Robertson 1976; McDonald 2018).

For several other postcranial features, S. uccasamamensis, together with P. acutidens and G. chapadmalense, show plesiomorphic conditions, whereas the derived conditions are observed in the remaining Mylodontini. For these features, the morphologies observed in $S$. uccasamamensis are more reminiscent of Scelidotheriinae and/or Lestodontini, rather than Pleistocene Mylodontini such as G. robustum and P. harlani (Owen 1842; Stock 1925).

Primitive features in the postcranial skeleton of S. uccasamamensis were identified for the humerus, radius, ulna, manus, tibia and pes (Boscaini et al. 2019a). These include, in the forelimb, the lack of a proximodistally vertical supinator crest on the humerus, the equally expanded lateral and medial humeral epicondyles, and the presence of a marked convexity of the anterior margin of the radius. In the manus, S. uccasamamensis shows peculiar trapezoid proportions and an occasionally-fused magnum and third metacarpal (Saint-André et al. 2010). In the hind limb, the tibia is mediolaterally narrow relative to its total length, and possesses two deep grooves for tendons on the posteromedial margin of the distal tibial epiphysis. In the pes, S. uccasamamensis exhibits a marked sustentacular process of the calcaneum and a sulcus tali of the astragalus, a relatively gracile third metatarsal which maintains a contact with the second metatarsal, and a fifth metatarsal showing an arched ventral profile in lateral view. The presence of these features contributes to the phylogenetic placement S. uccasamamensis at the base of Mylodontini, together with other Neogene taxa such as P. acutidens and G. chapadmalense (Boscaini et al. 2019a). However, as previously noted, the postcranium of the latter two taxa is largely unknown.

From a morphofunctional point of view, some preliminary, qualitative considerations on the postcranial elements of S. uccasamamensis can be discussed. Some of the distinctive features recognized in the present study are likely related to paleobiological factors such as 
digging capabilities and body size. Basically, the proportions and general features of the appendicular skeleton suggest that this animal was a terrestrial quadruped, without any clear locomotory specializations, and with a generally graviportal limb morphology (sensu Carrano 1999). Given the overall similarity of the appendicular proportions among $S$.

uccasamamensis and Pleistocene mylodontids, their center of mass likely occupied an analogous position (Bargo et al. 2000; Vizcaíno et al. 2001). Thus, the hind limb would have served mainly for supporting body mass and providing propulsion during locomotion, whereas the forelimb could have been more involved in other biological roles, such as digging and foraging. In this sense, the hind limb is more indicative of stance and locomotory habits than the forelimb.

The femoral greater trochanter in S. uccasamamensis is well developed, but it does not protrude proximally as far as the femoral head, suggesting a wide range of movements. The great development of the gluteal muscles, evidenced by the entheses development, indicates a marked stabilization of the hip joint. However, the relatively low position of the greater trochanter suggests a greater leverage for the gluteal group for femoral abduction (and lateral rotation of the pelvis during the swing phase of the contralateral limb), and reduced leverage for limb extension when compared to extant ambulatory herbivores of similar size (e.g., large bovids and rhinocerotids; Hildebrand \& Goslow 2001). The distal epiphysis of the femur in S. uccasamamensis is wide transversely and relatively shallow, with an almost flat patellar groove connected to asymmetrical femoral condyles, which are broader mediolaterally than they are deep anteroposteriorly (Fig. 9). This morphology is indicative of a plantigrade stance, with a more extended knee than in modern, similar-sized herbivores (de Toledo 1998). Proportions of both zeugopodia, which are short relative to the stylopodia, especially in the hind limb, indicate lower cursorial performance than in similar-sized modern bovids (de Toledo 1998). 
A preliminary body weight estimation for S. uccasamamensis was calculated using allometric equations established by Fariña et al. (1998) and Toledo et al. (2014). The value obtained of about $370 \mathrm{~kg}$, together with the general proportions of the limbs, allow us to exclude arboreality as a locomotory mode for S. uccasamamensis. Nevertheless, the bulky musculature that surely powered this animal, and the great development of entheses, could have allowed occasional climbing of rocks or trunks, as seen in similarly-sized living animals such as bears and large felids (Hildebrand \& Goslow 2001). The climbing performance of $S$. uccasamamensis likely was that of a slow and cautious animal. On the other hand, its body mass estimate is far less than that of other representatives of Mylodontinae, making this species one of the smallest members of a group characterized by many gigantic forms ( $\mathrm{BB}$, unpub. data). Accordingly, some primitive features of Simomylodon can be tentatively attributed to the absence of adaptations for supporting a gigantic body mass. For instance, fusion or simplification of joint surfaces, as described in larger mylodontids such as $G$. robustum and P. harlani (e.g., Owen 1842; Stock 1925; Cartelle et al. 2019) are not observed. Metatarsals are more gracile and elongated, resulting in a wider and less compact pes than in Paramylodon or Lestodon.

Since most extinct and extant xenarthrans exhibit clear specializations for digging, with the notable exception of extant sloths, it is likely that morphologies related to fossoriality are primitive for the sloth lineage and particularly developed in mylodontids (Pujos et al. 2012; Gaudin \& Croft 2015). In this sense, the general morphology of S. uccasamamensis is consistent with a certain degree of digging capability, as in many other Mylodontidae. However, in this taxon, humeral and ulnar entheses are less developed, the olecranon is less elongated, and autopodial elements are less bulky than in Glossotherium and Scelidotherium, a suite of postcranial features underscoring the absence of strong digging specialization in Simomylodon. For this reason, S. uccasamamensis was probably not an active digger, and 
was likely not a cave excavator, as has been inferred for some Pleistocene South-American mylodontids (Bargo et al. 2000; Vizcaíno et al. 2001). Burrowing habits in Pleistocene mylodontid sloths from the southern cone was a probable strategy to escape predation from large carnivores, which entered from North into South America during the Great American Biotic Interchange (Vizcaíno et al. 2001; Woodburne et al. 2010). So far, neither large-sized cave systems, nor fossil remains of North American putative predators have been recovered in the Pliocene of the Bolivian Altiplano (Marshall et al. 1983; Hoffstetter 1986; Marshall \& Sempéré 1991; Anaya \& MacFadden 1995). This suggests that the digging abilities of $S$. uccasamamensis were more likely related to foraging than to a defence strategy.

\section{CONCLUSIONS}

The newly documented postcranial elements of Simomylodon uccasamamensis substantially increase our knowledge of the anatomy and inferred locomotory behavior of this extinct sloth, which was a common faunal element in the late Miocene-late Pliocene deposits of the Bolivian Altiplano. The appendicular skeleton of S. uccasamamensis is reminiscent of that of larger Pleistocene relatives, such as Glossotherium robustum and Paramylodon harlani. However, some features are also shared with the postcrania of scelidotheriine and lestodontine sloths, and contribute to placing S. uccasamamensis in a relatively basal position among Mylodontini. Thanks to its remarkable skeletal completeness, S. uccasamamensis represents the best known early member of Mylodontini, and a key taxon for understanding the evolution of the entire clade. General morphology of both the forelimb and the hind limb of S. uccasamamensis indicate that this medium-sized mammal was engaged in a form of terrestrial quadrupedalism, with a graviportal aspect, including moderate climbing and digging abilities in its locomotor repertoire. The abundance of skeletal remains of $S$. 
uccasamamensis in several Bolivian localities reflects the widespread geographic distribution and ecological importance of this taxon in the Pliocene of the Andean Altiplano.

Acknowledgments. We thank R.D.E. MacPhee, J.J. Flynn, J. Galkin and M. Rios-Dickson (AMNH), B.J. MacFadden, J.I. Bloch and R.C. Hulbert, Jr. (FLMNH), K.D. Angielczyk, W. Simpson and A. Stroup (FMNH), L. Chornogubsky, M. Ezcurra, A. Kramarz, P. Teta, G. Cassini and S. Lucero (MACN), M.A. Reguero, S.C. Scarano and M.L. de los Reyes (MLP), C. de Muizon and G. Billet (MNHN), K. Seymour (ROM), A. Rincón (IVIC) and R. Sánchez (AMU-CURS), who kindly gave access to the specimens under their care. We also want to thank J.V. Tejada-Lara and M. Ubilla for sharing photographs of some fossil specimens. This paper greatly benefited from thoughtful comments and accurate revisions by Prof. G. De Iuliis, an anonymous reviewer and the Editor S. Thomas. The data collection for the present study was greatly facilitated by funding from the FMNH, the AMNH, the FLMNH and the University of Tennessee at Chattanooga. This research was made possible thanks to the cooperation agreement between the MNHN-Bol, the IANIGLA and the ISEM (CONICET Cooperation Agreement $\mathrm{N}^{\circ} 864 / 2014$ ), and actively funded by the cooperative programme ECOS-FonCyT (A14U01) and the National Geographic Society (projects NGS 9971-16 and EC-44712R-18).

\section{DATA ARCHIVING STATEMENT}

Data for this study are available in the Dryad Digital Repository:

https://datadryad.org/stash/share/IoTnzKIgnPeYYFn9CGQI8U9FLNVla3j9qcOmQo

\section{$\underline{\mathrm{XfkWI}}$}

Appendix S1. Simomylodon uccasamamensis - Referred material

Appendix S2. Comparison taxa - List of observed specimens 
Appendix S3. Simomylodon uccasamamensis - Measurements

\section{REFERENCES}

AMSON, E., ARGOT, C., McDONALD, H.G. and DE MUIZON, C. 2015a. Osteology and functional morphology of the forelimb of the marine sloth Thalassocnus (Mammalia, Tardigrada). Journal of Mammalian Evolution, 22, 169-242.

---, ---, ---, --- 2015b. Osteology and functional morphology of the hind limb of the marine sloth Thalassocnus (Mammalia, Tardigrada). Journal of Mammalian Evolution, 22, $355-419$.

ANAYA, F. and MacFADDEN, B.J. 1995. Pliocene mammals from Inchasi, Bolivia: the endemic fauna just before the Great American Interchange. Bulletin of the Florida Museum of Natural History, 39, 87-140.

BARGO, M.S., VIZCAÍNO, S.F., ARCHUBY, F.M. and BLANCO, R.E. 2000. Limb bone proportions, strength and digging in some Lujanian (Late Pleistocene-Early Holocene) mylodontid ground sloths (Mammalia: Xenarthra). Journal of Vertebrate Paleontology, 20, 601-610.

BOSCAINI, A., PUJOS, F., GAUDIN, T.J. 2019a. A reappraisal of the phylogeny of Mylodontidae (Mammalia, Xenarthra) and the divergence of mylodontine and lestodontine sloths. Zoologica Scripta, 48, 691-710.

---, GAUDIN, T.J., MAMANI QUISPE, B., MÜNCH, P., ANTOINE, P-O. and PUJOS, F. 2019b. New well-preserved craniodental remains of Simomylodon uccasamamensis (Xenarthra: Mylodontidae) from the Pliocene of the Bolivian Altiplano: phylogenetic, chronostratigraphic and palaeobiogeographical implications. Zoological Journal of the Linnean Society, 185, 459-486. 
---, ---, TOLEDO, N., MAMANI QUISPE, B., ANTOINE, P-O. and PUJOS, F. 2019c. The earliest well-documented occurrence of sexual dimorphism in extinct sloths: evolutionary and palaeoecological insights. Zoological Journal of the Linnean Society, 187, 229-239.

BRAMBILLA, L., TOLEDO, M.J., HARO, J.A. and AGUILAR, J.L. 2019. New osteoderm morphotype (xenarthra, mylodontidae) from the middle pleistocene of Argentina. Journal of South American Earth Sciences, 95, 102298.

CARRANO, M.T. 1999. What, if anything, is a cursor? Categories versus continua for determining locomotor habit in mammals and dinosaurs. Journal of Zoology, 247, 2942.

CARTELLE, C. 1980. Estudo comparativo do rádio e esqueleto da mão de Glossotherium (Ocnotherium) giganteum Lund, 1842. Anais da Academia Brasileira de Ciências, 52, $359-377$.

---, DE IULIIS, G., BOSCAINI, A. and PUJOS, F. 2019. Anatomy, possible sexual dimorphism, and phylogenetic affinities of a new mylodontine sloth from the Late Pleistocene of intertropical Brazil. Journal of Systematic Palaeontology, 23, 19571988.

COPE, E.D. 1889. The Edentata of North America. American Naturalist, 23, 657-664.

DE IULIIS, G., BOSCAINI, A., PUJOS, F., McAFEE, R.K., CARTELLE, C., TSUJI, L.J.S. and ROOK, L. In press. On the status of the giant mylodontine sloth Glossotherium wegneri (Xenarthra, Folivora) from the Late Pleistocene of Ecuador. Comptes rendus Palevol.

DE TOLEDO, P.M. 1998. Locomotory patterns within the Pleistocene sloths. Museu Paraense Emílio Goeldi, Belém, 192 pp. 
DELSUC, F., CATZEFLIS, F.M., STANHOPE, M.J. and DOUZERY, E.J.P. 2001. The evolution of armadillos, anteaters and sloths depicted by nuclear and mitochondrial phylogenies: implications for the status of the enigmatic fossil Eurotamandua. Proceedings of the Royal Society B, 268, 1605-1615.

---, KUCH, M., GIBB, G.C., KARPINSKI, E., HACKENBERGER, D., SZPAK, P., MARTÍNEZ, J.G., MEAD, J.I., McDONALD, H.G., MacPHEE, R.D.E., BILLET, G., HAUTIER, L. and POINAR, H.N. 2019. Ancient mitogenomes reveal the evolutionary history and biogeography of sloths. Current Biology, 29, 2031-2042.

ENGELMANN, G.F. 1985. The phylogeny of the Xenarthra. 51-64. In MONTGOMERY, G. G. (ed.) The evolution and Ecology of Armadillos, Sloths and Vermilinguas. Smithsonian Institution Press, Washington, DC, and London, UK, 451 pp.

EVANS, H.E. and DE LAHUNTA, A. 2013. Miller's Anatomy of the Dog. $4^{\text {th }}$ edn. Elsevier, St. Louis. $850 \mathrm{pp}$.

FARIÑA, R.A., VIZCAÍNO, S.F. and BARGO, M.S. 1998. Body mass estimations in Lujanian (Late Pleistocene-Early Holocene of South America) mammal megafauna. Mastozoología Neotropical, 5, 87-108.

FLOWER, W.H. 1883. On the arrangement of the orders and families of existing Mammalia. Proceedings of the Zoological Society of London, 51, 178-186.

GAUDIN, T.J. 2004. Phylogenetic relationships among sloths (Mammalia, Xenarthra, Tardigrada): the craniodental evidence. Zoological Journal of the Linnean Society, 140, 255-305.

GAUDIN, T.J. and CROFT, D.A. 2015. Paleogene Xenarthra and the evolution of South American mammals. Journal of Mammalogy, 96, 622-634.

GERVAIS, P. 1873. Mémoire sur plusieurs espèces de Mammifères fossiles propres à l’Amérique méridionale. Mémoires de la Société Géologique de France, 9, 1-44. 
GILL, T. 1872. Arrangement of the families of mammals, with analytical tables. Smithsonian Miscellaneous Collections, 11, 1-98.

HARO, J.A., TAUBER, A.A. and KRAPOVICKAS, J.M. 2016. The manus of Mylodon darwinii Owen (Tardigrada, Mylodontidae) and its phylogenetic implications. Journal of Vertebrate Paleontology, 36, e1188824.

HILDEBRAND, M. and GOSLOW, G. 2001. Analysis of vertebrate structure. $5^{\text {th }}$ edn. Wiley, New York, NY, 635 pp.

HIRSCHFELD, S.E. 1985. Ground sloths form the Friasian La Venta Fauna, with additions to the Pre-Friasian Coyaima Fauna of Colombia, South America. University of California Publications in Geological Sciences, 128, 1-91.

HOFFSTETTER, R. 1986. High andean mammalian faunas during the Plio-Pleistocene. 219245. In VUILLEUMIER, F. and MONASTERIO, M. (eds). High altitude tropical biogeography. New York, NY, 649 pp.

KRAGLIEVICH, L. 1925. Cuatro nuevos Gravigrados de la fauna araucana chapadmalense. Anales del Museo Nacional de Historia Natural "Bernardino Rivadavia", 33, 215235.

--- 1926. Notas sobre gravígrados de Sud América. I. Indicios de evolución progresiva en dos astrágalos y un calcáneo de Megatherium. Anales del Museo Nacional de Historia Natural de Buenos Aires, 34, 21-29.

MARIOTTI, V., FACCHINI, F. and BELCASTRO, M.G. 2007. The study of entheses: proposal of a standardised scoring method for twenty-three entheses of the postcranial skeleton. Collegium antropologicum, 31, 291-313.

MARSHALL, L.G. and SEMPÉRÉ, T. 1991. The Eocene to Pleistocene vertebrates of Bolivia and their stratigraphic context: a review. 631-652. In SUÁREZ-SORUCO, R. 
(ed.). Fósiles y facies de Bolivia - Vol. I Vertebrados. Yacimientos Petrolíferos Fiscales Bolivianos, Santa Cruz, Bolivia, 359 pp.

---, HOFFSTETTER, R. and PASCUAL, R. 1983. Mammals and stratigraphy: geochronology of the continental mammal-bearing Tertiary of South America. Palaeovertebrata (Mémoire Extraordinaire): 1-93.

McAFEE, R.K. 2016. Description of new postcranial elements of Mylodon darwinii Owen 1839 (Mammalia: Pilosa: Mylodontinae), and functional morphology of the forelimb. Ameghiniana, 53, 418-443.

McDONALD, H.G. 1977. Description of the osteology of the extinct gravigrade edentate, Megalonyx, with observations on its ontogeny, phylogeny and functional anatomy. Unpublished Master thesis, University of Florida, Gainesville, 328 pp.

--- 1987. A systematic review of the Plio-Pleistocene scelidotheriine ground sloths (Mammalia: Xenarthra: Mylodontidae). Unpublished PhD Thesis, University of Toronto, Toronto, $478 \mathrm{pp}$.

--- 2003. Xenarthran skeletal anatomy: primitive or derived? (Mammalia, Xenarthra). Senckenbergiana biologica, 83, 5-18.

--- 2018. An overview of the presence of osteoderms in sloths: implications for osteoderms as a plesiomorphic character of the Xenarthra. Journal of Mammalian Evolution, 25, $485-493$.

--- and DE IULIIS, G. 2008. Fossil history of sloths. 39-55. In VIZCAÍNO, S. F. and LOUGHRY, W. J. (eds). The Biology of the Xenarthra. The University of Florida Press, Gainesville, FL, 370 pp.

McKENNA, M.C. and BELL, S.K. 1997. Classification of Mammals above the Species Level. Columbia University Press, New York, NY. 631 pp. 
MEREDITH, R.W., JANEČKA, J.E., GATESY, J., RYDER, O.A., FISHER, C.A., TEELING, E.C., GOODBLA, A., EIZIRIK, E., SIMÃO, T.L.L., STADLER, T., RABOSKY, D.L., HONEYCUTT, R.L., FLYNN, J.J., INGRAM, C.M., STEINER, C., WILLIAMS, T.L., ROBINSON, T.J., BURK-HERRICK, A., WESTERMAN, M., AYOUB, N.A., SPRINGER, M.S. and MURPHY, W.J. 2011. Impacts of the Cretaceous terrestrial revolution and $\mathrm{KPg}$ extinction on mammal diversification. Science, 334, 521-524.

MONTELLANO-BALLESTEROS, M. and CARRANZA-CASTAÑEDA, Ó. 1986. Descripción de un milodóntido del Blancano temprano de La Mesa Central de México. Universidad Nacional Autónoma de Mexico, Instituto de Geología, Revista, 6, 193-203.

NASIF, N.L., ESTEBAN, G. and GEORGIEFF, S.M. 2008. Nuevo registro de vertebrados para la Formación Aconquija, provincia de Catamarca, Noroeste de Argentina. Implicancias cronoestratigráficas y consideraciones paleoambientales. Acta Geologica Lilloana, 20, 99-112.

O'LEARY, M.A., BLOCH, J.I., FLYNN, J.J., GAUDIN, T.J., GIALLOMBARDO, A., GIANNINI, N.P., GOLDBERG, S.L., KRAATZ, B.P., LUO, Z-X., MENG, J., NI, X., NOVACEK, M.J., PERINI, F.A., RANDALL, Z.S., ROUGIER, G.W., SARGIS, E.J., SILCOX, M.T., SIMMONS, N.B., SPAULDING, M., VELAZCO, P.M., WEKSLER, M., WIBLE, J.R. and CIRRANELLO, A.L. 2013. The placental mammal ancestor and the post-K-Pg radiation of placentals. Science, 339, 662-667.

OWEN, R. 1842. Description of the skeleton of an extinct gigantic sloth, Mylodon robustus, Owen with observations on the osteology, natural affinities, and probable habits of the megatheroid quadrupeds in general. R. \& J.E. Taylor, London, 176 pp. 
PITANA, V.G. 2011. Estudo do gênero Glossotherium Owen, 1840 (Xenarthra, Tardigrada, Mylodontidae), Pleistoceno do Estado do Rio Grande do Sul, Brasil. Unpublished Master Thesis, Universidade Federal do Rio Grande do Sul, Porto Alegre, 183 pp. PRESSLEE, S., SLATER, G.J., PUJOS, F., FORASIEPI, A.M., FISCHER, R., MOLLOY, K., MACKIE, M., OLSEN, J.V., KRAMARZ, A., TAGLIORETTI, M., SCAGLIA, F., LEZCANO, M., LANATA, J.L., SOUTHON, J., FERANEC, R., BLOCH, J., HAJDUK, A., MARTIN, F.M., SALAS GISMONDI, R., REGUERO, M., DE MUIZON, C., GREENWOOD, A., CHAIT, B.T., PENKMAN, K., COLlinS, M., MacPHEE, R.D.E. 2019. Palaeoproteomics resolves sloth relationships. Nature Ecology \& Evolution, 3, 1121-1130.

PUJOS, F. and DE IULIIS, G. 2007. Late Oligocene Megatherioidea Fauna (Mammalia: Xenarthra) from Salla-Luribay (Bolivia): new data on basal sloth radiation and Cingulata-Phyllophaga split. Journal of Vertebrate Paleontology, 27, 132-144.

---, GAUDIN, T.J., DE IULIIS, G. and CARTELLE, C. 2012. Recent advances on variability, morpho-functional adaptations, dental terminology, and evolution of sloths. Journal of Mammalian Evolution, 19, 159-169.

---, DE IULIIS, G. and CARTELLE, C. 2017. A paleogeographic overview of tropical fossil sloths: towards an understanding of the origin of extant suspensory sloths? Journal of Mammalian Evolution, 24, 19-38.

QUIÑONES, S.I., MIÑO-BOILINI, Á.R., ZURITA, A.E., CONTRERAS, S.A., LUNA, C.A., CANDELA, A.M., CAMACHO, M., ERCOLI, M.D., SOLÍS, N. and BRANDONI, D. 2019. New records of Neogene Xenarthra (Mammalia) from eastern Puna (Argentina): diversity and biochronology. Journal of Paleontology, 93, 12581275.

RAUTENBERG, M. 1906. Über Pseudolestodon hexaspondylus. Palaeontographica, 
$53,1-50$.

RINCÓN, A.D., SOLÓRZANO, A., McDONALD, H.G. and FLORES, M.N. 2016.

Baraguatherium takumara, gen. et sp. nov., the earliest mylodontoid sloth (Early

Miocene) from northern South America. Journal of Mammalian Evolution, 24, 179-

191.

ROBERTSON, J.S. 1976. Latest Pliocene mammals from Haile XV A, Alachua County, Florida. Bulletin of the Florida Museum of Natural History, 20, 111-186.

ROSE, K.D. and EMRY, R.J. 1993. Relationships of Xenarthra, Pholidota, and fossil "edentates": the morphological evidence. 81-102. In SZALAY, F.S., NOVACEK, M.J. and McKENNA, M.C. (eds.) Mammal Phylogeny: Placentals. Springer, New York, NY, 321 pp.

ROVERETO. C. 1914. Los estratos araucanos y sus fósiles. Anales del Museo Nacional de Buenos Aires, 25, 1-249.

SAINT-ANDRÉ, P-A. 1994. Contribution à l'étude des grands mammifères du Néogène de l'altiplano bolivien. Unpublished $\mathrm{PhD}$ Thesis, Museum national d'Histoire naturelle de Paris, Paris, 664 pp.

SAINT-ANDRÉ, P-A., PUJOS, F., CARTELLE, C., DE IULIIS, G., GAUDIN, T.J., McDONALD, H.G. and MAMANI QUISPE, B. 2010. Nouveaux paresseux terrestres (Mammalia, Xenarthra, Mylodontidae) du Néogène de l'Altiplano bolivien. Geodiversitas, 32, 255-306.

SHOCKEY, B.J. and ANAYA, F. 2011. Grazing in a new late Oligocene mylodontid sloth and a mylodontid radiation as a component of the Eocene-Oligocene faunal turnover and the early spread of grasslands/savannas in South America. Journal of Mammalian Evolution, 18, 101-115. 
STOCK, C. 1925. Cenozoic gravigrade Edentates of Western North America with special reference to the Pleistocene Megalonychinae, and Mylodontidae of Rancho La Brea. Carnegie Institution of Washington, Publications, 331, 1-206.

TOLEDO, N., BARGO, M.S. and VIZCAÍNO, S.F. 2013. Muscular reconstruction and functional morphology of the forelimb of early Miocene sloths (Xenarthra, Folivora) of Patagonia. The Anatomical Record, 296, 305-325.

---, CASSINI, G.H., VIZCAÍNO, S.F. and BARGO, M.S. 2014. Mass estimation of Santacrucian sloths from the Early Miocene Santa Cruz Formation of Patagonia, Argentina. Acta Palaeontologica Polonica, 59, 267-280.

---, BARGO, M.S. and VIZCAÍNO, S.F. 2015. Muscular reconstruction and functional morphology of the hind limb of santacrucian (early Miocene) sloths (Xenarthra, Folivora) of Patagonia. The Anatomical Record, 298, 842-864.

VARELA, L., TAMBUSSO, P.S., McDONALD, H.G. and FARIÑA, R.A. 2018. Phylogeny, macroevolutionary trends and historical biogeography of sloths: insights from a Bayesian morphological clock analysis. Systematic Biology, 68, 204-218.

VARGAS-PEIXOTO, D., COLUSSO, C.S., DA-ROSA, Á.A.S. and KERBER, L. 2019. A new record of Lestodon armatus Gervais 1855 (Xenarthra, Mylodontidae) from the Quaternary of southern Brazil and remarks on its postcranial anatomy. Historical Biology, published online 2 April 2019. doi:10.1080/08912963.2019.1597075 VIZCAÍNO, S.F., ZÁRATE, M., BARGO, M.S. and DONDAS, A. 2001. Pleistocene burrows in the Mar del Plata area (Argentina) and their probable builders. Acta Palaeontologica Polonica, 46, 289-301.

WEBB, S.D. 1989. Osteology and relationships of Thinobadistes segnis, the first mylodont sloth in North America. 469-532. In REDFORD, K.H. and EISENBERG, J.F. (eds.) Advances in Neotropical Mammalogy. Sandhill Crane Press, Gainesville, FL, 614 pp. 
WINGE, H. 1915. Jordfundne og nulevende Gumlere (Edentata) fra Lagoa Santa, Minas Geraes, Brasilien. Bianco Lunos, Copenhagen, 321 pp.

WOODBURNE, M.O. 2010. The great american biotic interchange: dispersals, tectonics, climate, sea level and holding pens. Journal of Mammalian Evolution, 17, 245-264.

\section{FIGURE CAPTIONS}

FIG. 1. Map of the late Neogene fossil-bearing localities of Bolivia in which the remains of the mylodontid sloth Simomylodon uccasamamensis have been recovered. Circles: cities; Stars: fossil localities.

[Suggested size: two-thirds page width]

FIG. 2. Left scapula of the mylodontid sloth Simomylodon uccasamamensis (MNHN-Bol V 3718) in lateral (A), proximal (B) and medial (C) views. Abbreviations: ap, acromion process; cf, clavicular fossa; cop, coracoid process; csf, coraco-scapular foramen; gc, glenoid cavity; isf, infraspinous fossa; por, posterior ridge of subscapular fossa; psf, post-scapular fossa; scs, secondary spine; ssf, supraspinous fossa; ssp, spine of scapula. Scale bar equals 5 $\mathrm{cm}$.

[Suggested size: two-thirds page width]

FIG. 3. Right humerus of the mylodontid sloth Simomylodon uccasamamensis (MNHN-Bol V 13367) in proximal (A), anterior (B) and distal (C) views. Abbreviations: aer, ascending entepicondylar ridge; cpt, capitulum; dc, deltoid crest; gt, greater tuberosity; hh, humeral head; lep, lateral epicondyle; lt, lesser tuberosity; mep, medial epicondyle; scr, supinator crest, tr, trochlea. Scale bar equals $5 \mathrm{~cm}$. 
[Suggested size: single column]

FIG. 4. Right radius of the mylodontid sloth Simomylodon uccasamamensis (MNHN-Bol V 3375 ) in anterior (A), lateral (B), posterior (C), medial (D), proximal (E) and distal (F) views. Abbreviations: cpf, capitular facet; luf, lunar facet; psp, pseudostyloid process; prr, pronator ridge; puf, proximal ulnar facet; rtu, radial tuberosity; scf, scaphoid facet; stp, styloid process; un, ulnar notch. Scale bar equals $5 \mathrm{~cm}$.

[Suggested size: full page width]

FiG. 5. Proximal fragment of left ulna of the mylodontid sloth Simomylodon uccasamamensis (MNHN-Bol V 3717) in anterior (A), lateral (B) and posterior (C) views. Abbreviations: ancp, anconeal process; cp, coronoid process; olec, olecranon; pm, posterior margin; rn, radial notch; $\operatorname{tn}(\mathrm{lp})$, trochlear notch (lateral portion); $\operatorname{tn}(\mathrm{mp})$, trochlear notch (medial portion). Scale bar equals $5 \mathrm{~cm}$.

[Suggested size: two-thirds page width]

Fig. 6. Carpals (A-P) and sesamoids (Q-T) of the mylodontid sloth Simomylodon uccasamamensis. A-B, left scaphoid (MNHN.F.AYO180) in distal (A) and dorsal (B) views; C-E, left lunar (MNHN.F.AYO111) in anterior (C), dorsal (D) and distal (E) views; F-H, left cuneiform (MNHN.F.AYO109) in proximal $(F)$, dorsal $(\mathrm{G})$ and distal $(\mathrm{H})$ views; I-K, left trapezoid (MNHN.F.AYO180) in proximal (I), posterior (J) and distal (K) views; L-N, right unciform (MNHN-Bol V 12953) in proximal (L), dorsal (M) and distal (N) views; O-P, right pisiform (MNHN.F.AYO180) in palmar (O) and oblique-palmar (P) views; Q-R, right medial sesamoid of mtc4 (MNHN.F.AYO114) in medial (Q) and lateral (R) views; S-T, right lateral sesamoid of mtc4 (MNHN.F.AYO111) in medial (S) and palmar (T) views. Black and white 
photos have been taken from St-André et al. (2010). Abbreviations refer to articular facets for the indicated bones, as follows: cmc, carpal-metacarpal complex; cu, cuneiform, lu, lunar; mg, magnum; mtc (2-3-4-5), metacarpal (2-3-4-5); pis, pisiform; rd, radius; sc, scaphoid; td, trapezoid; ul, ulna; un, unciform. Scale bar equals $2 \mathrm{~cm}$.

[Suggested size: full page width]

FIG. 7. Metacarpal elements of the mylodontid sloth Simomylodon uccasamamensis. A-B, right carpal-metacarpal complex (MNHN.F.VIZ32) in dorsal (A) and distal (B) views; C-E, right metacarpal II (MNHN.F.AYO190) in anterior (C), posterior (D) and proximal (E) views; F-H, right metacarpal III (MNHN.F.VIZ27) in dorsal (F), palmar (G) and proximal (H) views; I-M, left metacarpal III fused with magnum (MNHN.F.AYO179) in proximal (I), dorsal (J), posterior $(\mathrm{K})$, palmar (L) and anterior (M) views; N-P, proximal fragment of left metacarpal IV (MNHN.F.VIZ33) in proximal $(\mathrm{N})$, dorsal $(\mathrm{O})$ and posterior $(\mathrm{P})$ views; Q-S, left metacarpal V (MNHN-Bol V 13367) in anterior (Q), dorsal (R) and distal (S) views. Abbreviations refer to articular facets for the indicated bones, as follows: cmc, carpalmetacarpal complex; lu, lunar; mg, magnum; mtc (2-3-4-5), metacarpal (2-3-4-5); pp (1-2-35), proximal phalanx (1-2-3-5); sc, scaphoid; td, trapezoid; un, unciform. Scale bar equals 2 $\mathrm{cm}$.

[Suggested size: full page width]

FIG. 8. Manual phalanges of the mylodontid sloth Simomylodon uccasamamensis. A-C, right proximal phalanx of third digit (MNHN-Bol V 3313) in proximal (A), lateral (B) and distal (C) views; D-G, right intermediate phalanx of third digit (MNHN-Bol V 3313) in proximal (D), lateral (E), dorsal (F) and palmar (G) views; H-J, left ungual phalanx of first digit (MNHN.F.AYO180) in dorsal (H), medial (I) and palmar (J) views; K-M, left ungual phalanx 
of second digit (MNHN.F.AYO180) in dorsal (K), medial (L) and palmar (M) views; N-P, left ungual phalanx of third digit (MNHN.F.AYO180) in dorsal $(\mathrm{N})$, medial $(\mathrm{O})$ and palmar (P) views. Scale bar equals $2 \mathrm{~cm}$.

[Suggested size: full page width]

FIG. 9. Right femur of the mylodontid sloth Simomylodon uccasamamensis (MNHN-Bol V 3299) in lateral (A), anterior (B), medial (C), posterior (D), proximal (E) and distal (F) views. Abbreviations: fh, femoral head; gt, greater trochanter; icfo, intercondylar fossa; lco, lateral condyle; lec, lateral epicondyle; 1t, lesser trochanter; mco, medial condyle; mec, medial epicondyle; pg, patellar groove; tt, third trochanter. Scale bar equals $10 \mathrm{~cm}$.

[Suggested size: full page width]

FIG. 10. Tibia, patella, fibula, and cyamella of the mylodontid sloth Simomylodon uccasamamensis (MNHN-Bol V 12518). A-F, right tibia in lateral (A), anterior (B), medial (C), posterior (D), proximal (E) and distal (F) views; G-H, right patella in anterior (G) and posterior $(\mathrm{H})$ views; I-L, right fibula in medial $(\mathrm{I})$, lateral $(\mathrm{J})$, posterior $(\mathrm{K})$ and proximal $(\mathrm{L})$ views; M-N, right cyamella in lateral (M) and articular $(\mathrm{N})$ views. Abbreviations: af, astragalar facet; atg, anterior tibial groove (for $m$. tibialis caudalis); dff, distal fibular facet; dif, discoid process facet; dtf, distal tibial facet; fcf, fibular cyamella facet; femf, femoral facet; fibf, fibular facet; lco, lateral condyle; mco, medial condyle; odf, odontoid process facet; pff, proximal fibular facet; ptf, proximal tibial facet; ptg, posterior tibial groove; tcf, tibial cyamella facet; tibf, tibial facet; tt, tibial tuberosity. Scale bar equals $5 \mathrm{~cm}$. [Suggested size: full page width] 
FIG. 11. Left tibia, fibula, and cyamella of the mylodontid sloth Simomylodon uccasamamensis (MNHN-Bol V 12518) showing connections among the three elements, in lateral (A), posterior (B) and proximal (C) views. Scale bar equals $5 \mathrm{~cm}$.

[Suggested size: full page width]

FiG. 12. Calcaneum and astragalus of the mylodontid sloth Simomylodon uccasamamensis. A-D, right calcaneum (MNHN-Bol V 8541) in proximal (A), distal (B), lateral (C) and anterior (D) views; E-H, right astragalus (MNHN-Bol V 12518) in anterior (E), proximal (F), medial $(\mathrm{G})$ and lateral $(\mathrm{H})$ views. Abbreviations: cn, calcaneal neck; cub, cuboid facet; dif, discoid facet; ef, ectal facet; ff, fibular facet, navf, navicular facet; odp, odontoid process; st, sulcus tali; suf, sustentacular facet; tc, tuber calcis; tg, tendinous groove. Scale bar equals 5 $\mathrm{cm}$.

[Suggested size: full page width]

FIG. 13. Tarsal and metatarsal elements of the mylodontid sloth Simomylodon uccasamamensis. A-C, right navicular (MNHN-Bol V 8541) in distal (A), proximal (B) and lateral (C) views; D-G, right cuboid (MNHN-Bol V 12518) in dorsal (D), proximal (E), distal (F) and palmar (G) views; H-I, right ectocuneiform (MNHN-Bol V 12518) in proximal (H) and distal (I) views; J-N, right metatarsal III (MNHN-Bol V 13495) in dorsal (J), lateral (K), medial (L), proximal (M) and distal $(\mathrm{N})$ views; O-Q, proximal fragment of right metatarsal IV (MNHN.F.VIZ28) in proximal (O), lateral (P) and distal (Q) views; R-S, fragment of metatarsal V (MNHN-Bol V 13450) in proximal (R) and lateral (S) views. Abbreviations refer to articular facets for the indicated bones, as follows: ast, astragalus, cal, calcaneum; cub, cuboid; ec/mc, ectocuneiform and mesocuneiform; ect, ectocuneiform; mtt (2-3-4-5), metatarsal (2-3-4-5); nav, navicular. Scale bar equals $2 \mathrm{~cm}$. 
[Suggested size: full page width]

FIG. 14. Dermal ossicles of the mylodontid sloth Simomylodon uccasamamensis (MNHNBol V 3726) from the early Pliocene of Casira, Bolivia. Scale bar equals $2 \mathrm{~cm}$.

[Suggested size: single column] 


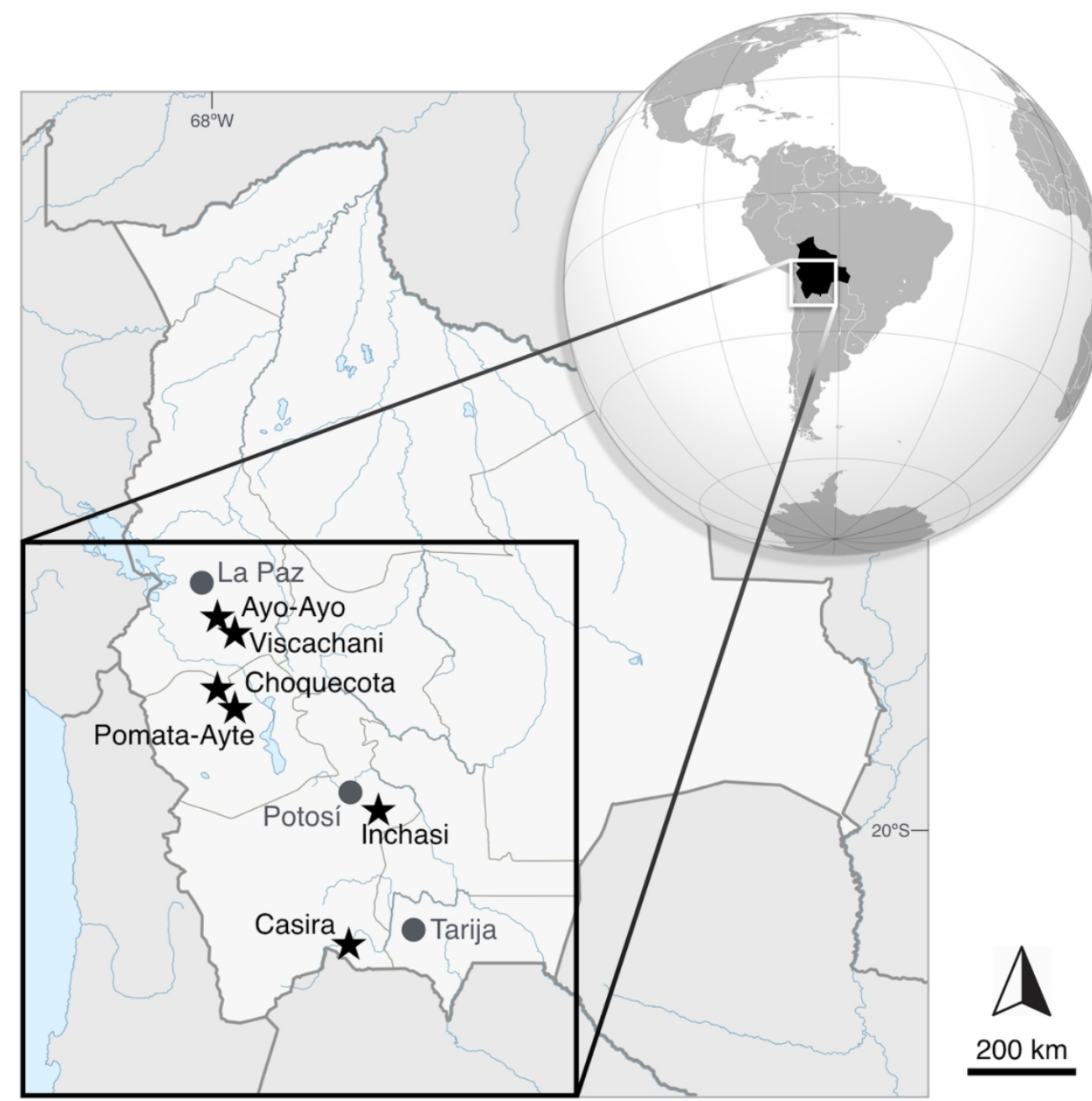

Fig. 1. Map of the late Neogene fossil-bearing localities of Bolivia in which the remains of the mylodontid sloth Simomylodon uccasamamensis have been recovered. Circles: cities; Stars: fossil localities. [Suggested size: two-thirds page width]

$109 \times 109 \mathrm{~mm}(300 \times 300 \mathrm{DPI})$ 


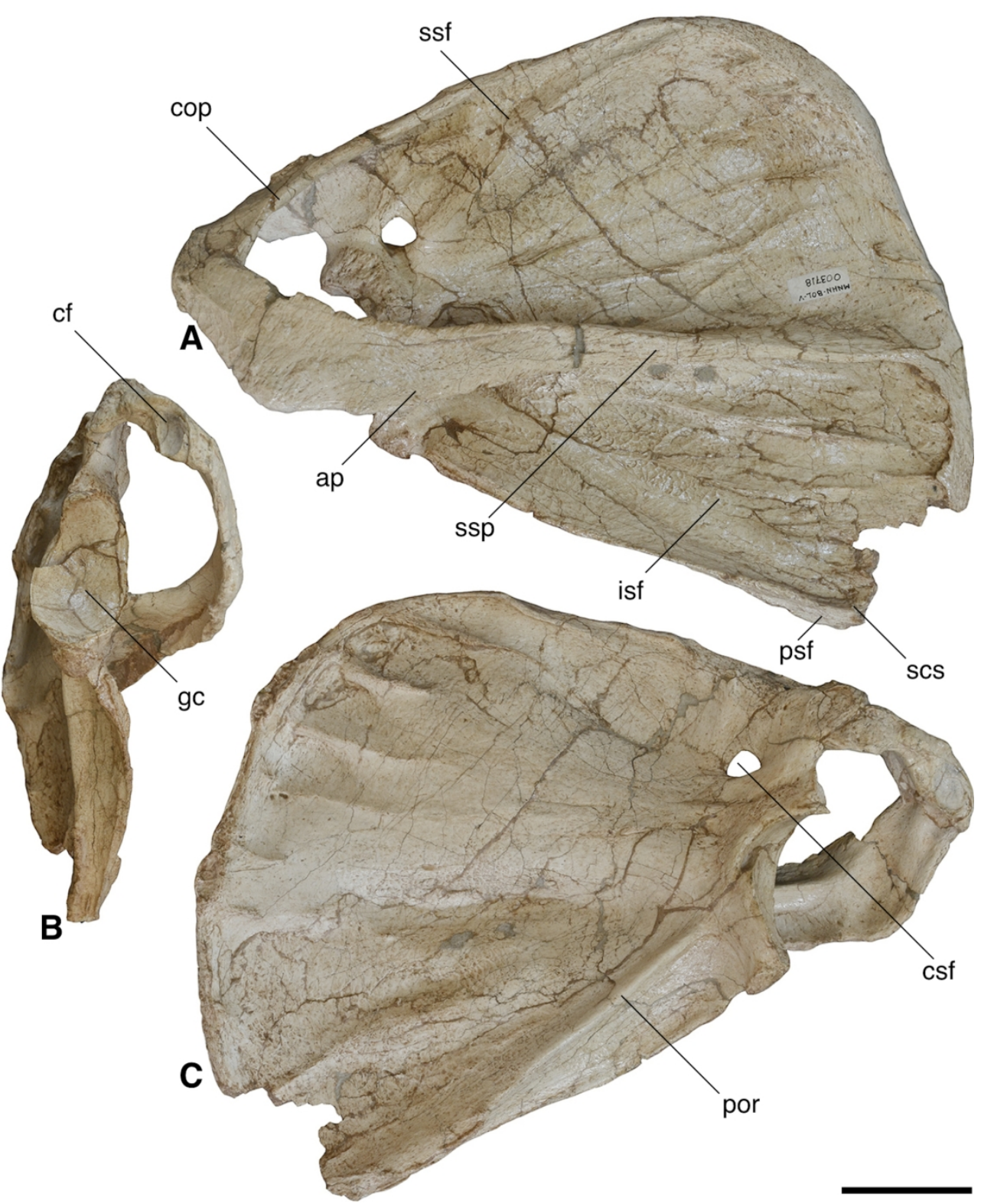

Fig. 2. Left scapula of the mylodontid sloth Simomylodon uccasamamensis (MNHN-Bol V 3718) in lateral (A), proximal (B) and medial (C) views. Abbreviations: ap, acromion process; cf, clavicular fossa; cop, coracoid process; csf, coraco-scapular foramen; gc, glenoid cavity; isf, infraspinous fossa; por, posterior ridge of subscapular fossa; psf, post-scapular fossa; scs, secondary spine; ssf, supraspinous fossa; ssp, spine of scapula. Scale bar equals $5 \mathrm{~cm}$.

$109 \times 134 \mathrm{~mm}(600 \times 600 \mathrm{DPI})$ 


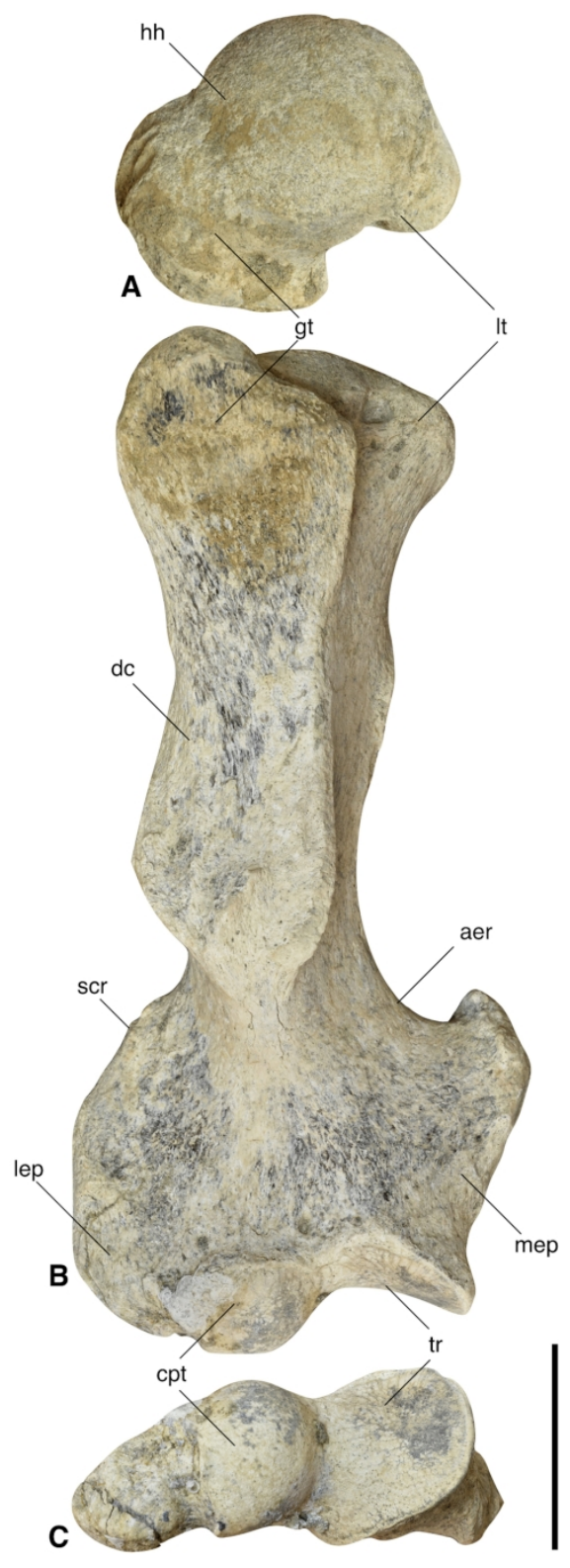

Fig. 3. Right humerus of the mylodontid sloth Simomylodon uccasamamensis (MNHN-Bol V 13367) in proximal (A), anterior (B) and distal (C) views. Abbreviations: aer, ascending entepicondylar ridge; cpt, capitulum; dc, deltoid crest; gt, greater tuberosity; hh, humeral head; lep, lateral epicondyle; It, lesser tuberosity; mep, medial epicondyle; scr, supinator crest, tr, trochlea. Scale bar equals $5 \mathrm{~cm}$.

\section{$80 \times 223 \mathrm{~mm}(600 \times 600 \mathrm{DPI})$}




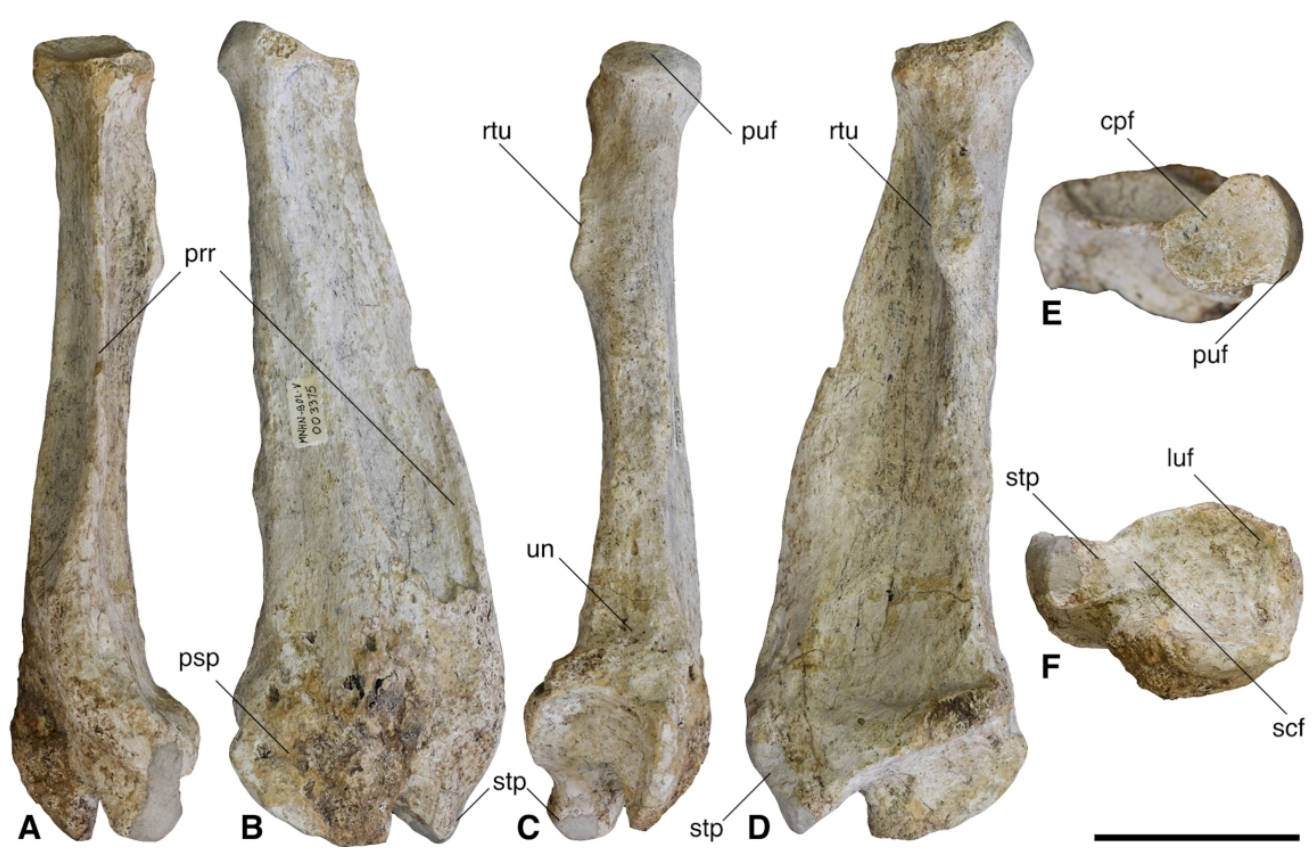

Fig. 4. Right radius of the mylodontid sloth Simomylodon uccasamamensis (MNHN-Bol V 3375) in anterior $(A)$, lateral (B), posterior (C), medial (D), proximal (E) and distal (F) views. Abbreviations: cpf, capitular facet; luf, lunar facet; psp, pseudostyloid process; prr, pronator ridge; puf, proximal ulnar facet; rtu, radial tuberosity; scf, scaphoid facet; stp, styloid process; un, ulnar notch. Scale bar equals $5 \mathrm{~cm}$.

$165 \times 105 \mathrm{~mm}(600 \times 600 \mathrm{DPI})$ 

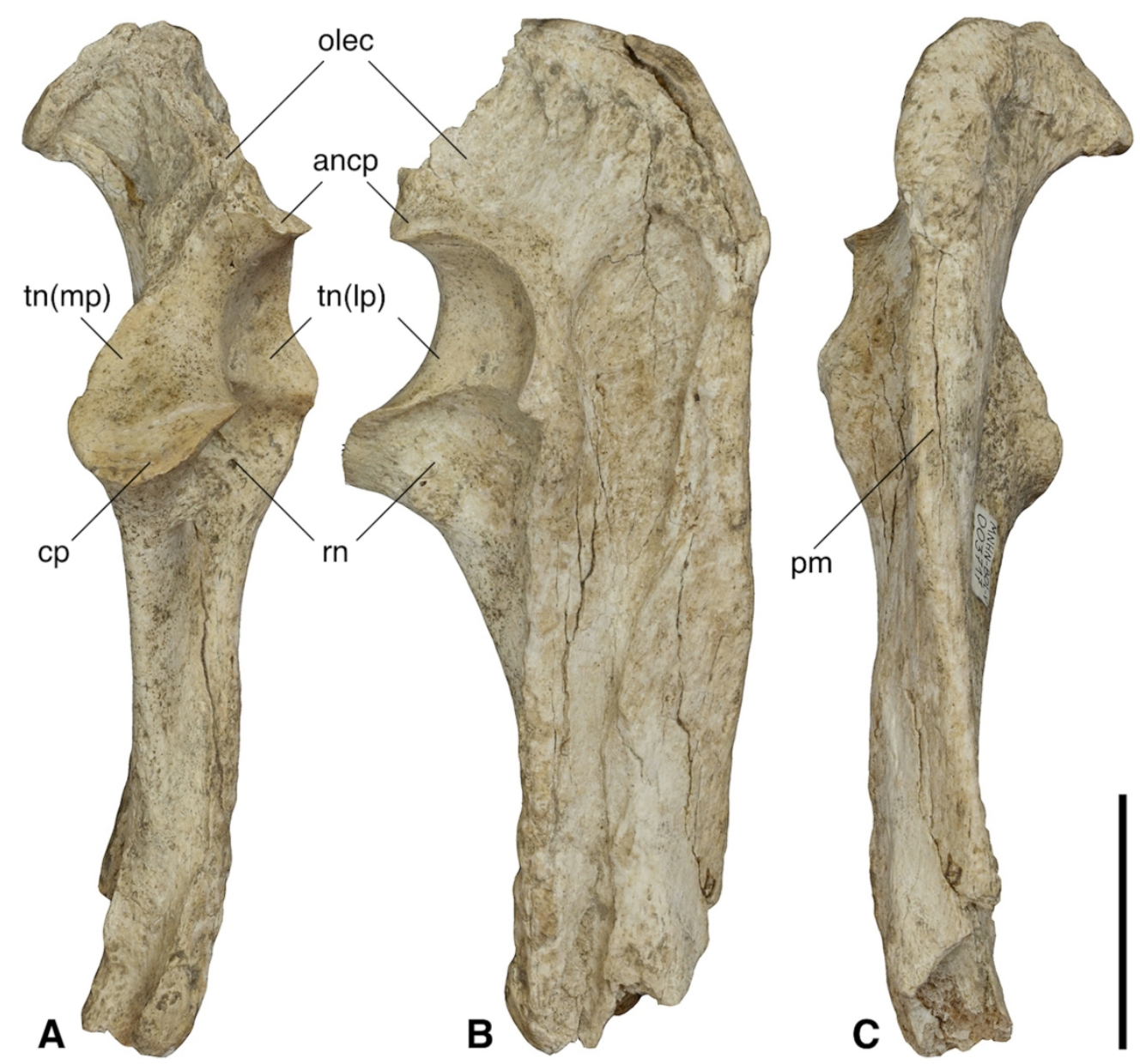

Fig. 5. Proximal fragment of left ulna of the mylodontid sloth Simomylodon uccasamamensis (MNHN-Bol V 3717 ) in anterior (A), lateral (B) and posterior (C) views. Abbreviations: ancp, anconeal process; $\mathrm{cp}$, coronoid process; olec, olecranon; pm, posterior margin; rn, radial notch; $t n(I p)$, trochlear notch (lateral portion); $\operatorname{tn}(\mathrm{mp})$, trochlear notch (medial portion). Scale bar equals $5 \mathrm{~cm}$.

$109 \times 103 \mathrm{~mm}(600 \times 600 \mathrm{DPI})$ 


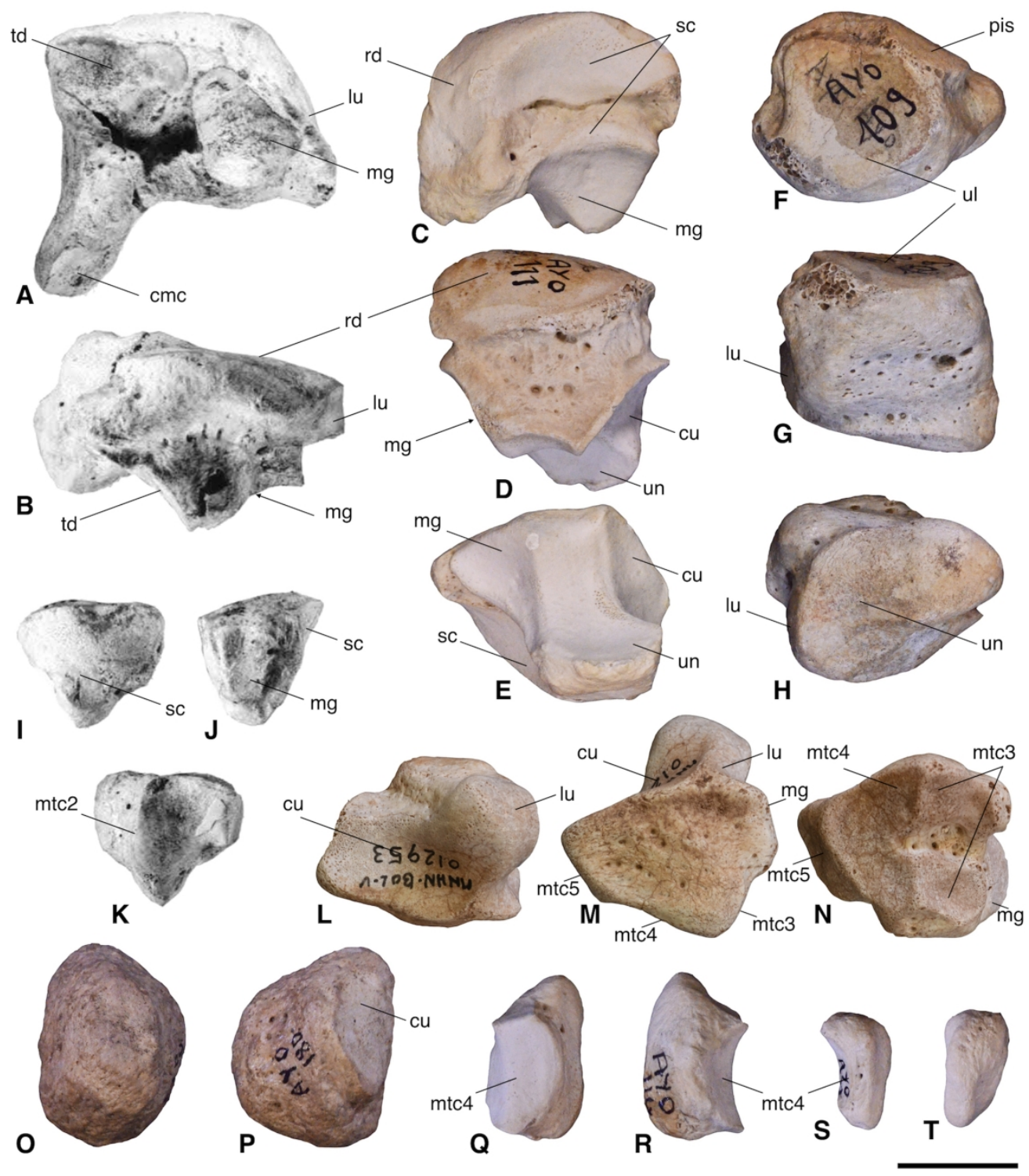

Fig. 6. Carpals (A-P) and sesamoids (Q-T) of the mylodontid sloth Simomylodon uccasamamensis. A-B, left scaphoid (MNHN.F.AYO180) in distal (A) and dorsal (B) views; C-E, left lunar (MNHN.F.AYO111) in anterior (C), dorsal (D) and distal (E) views; F-H, left cuneiform (MNHN.F.AYO109) in proximal (F), dorsal (G) and distal (H) views; I-K, left trapezoid (MNHN.F.AYO180) in proximal (I), posterior (J) and distal (K) views; L$\mathrm{N}$, right unciform (MNHN-Bol V 12953) in proximal (L), dorsal (M) and distal (N) views; O-P, right pisiform (MNHN.F.AYO180) in palmar (O) and oblique-palmar (P) views; Q-R, right medial sesamoid of mtc4 (MNHN.F.AYO114) in medial (Q) and lateral (R) views; S-T, right lateral sesamoid of mtc4 (MNHN.F.AYO111) in medial (S) and palmar (T) views. Black and white photos have been taken from StAndré et al. (2010). Abbreviations refer to articular facets for the indicated bones, as follows: cmc, carpalmetacarpal complex; cu, cuneiform, lu, lunar; mg, magnum; mtc (2-3-4-5), metacarpal (2-3-4-5); pis, pisiform; rd, radius; sc, scaphoid; td, trapezoid; ul, ulna; un, unciform. Scale bar equals $2 \mathrm{~cm}$. 


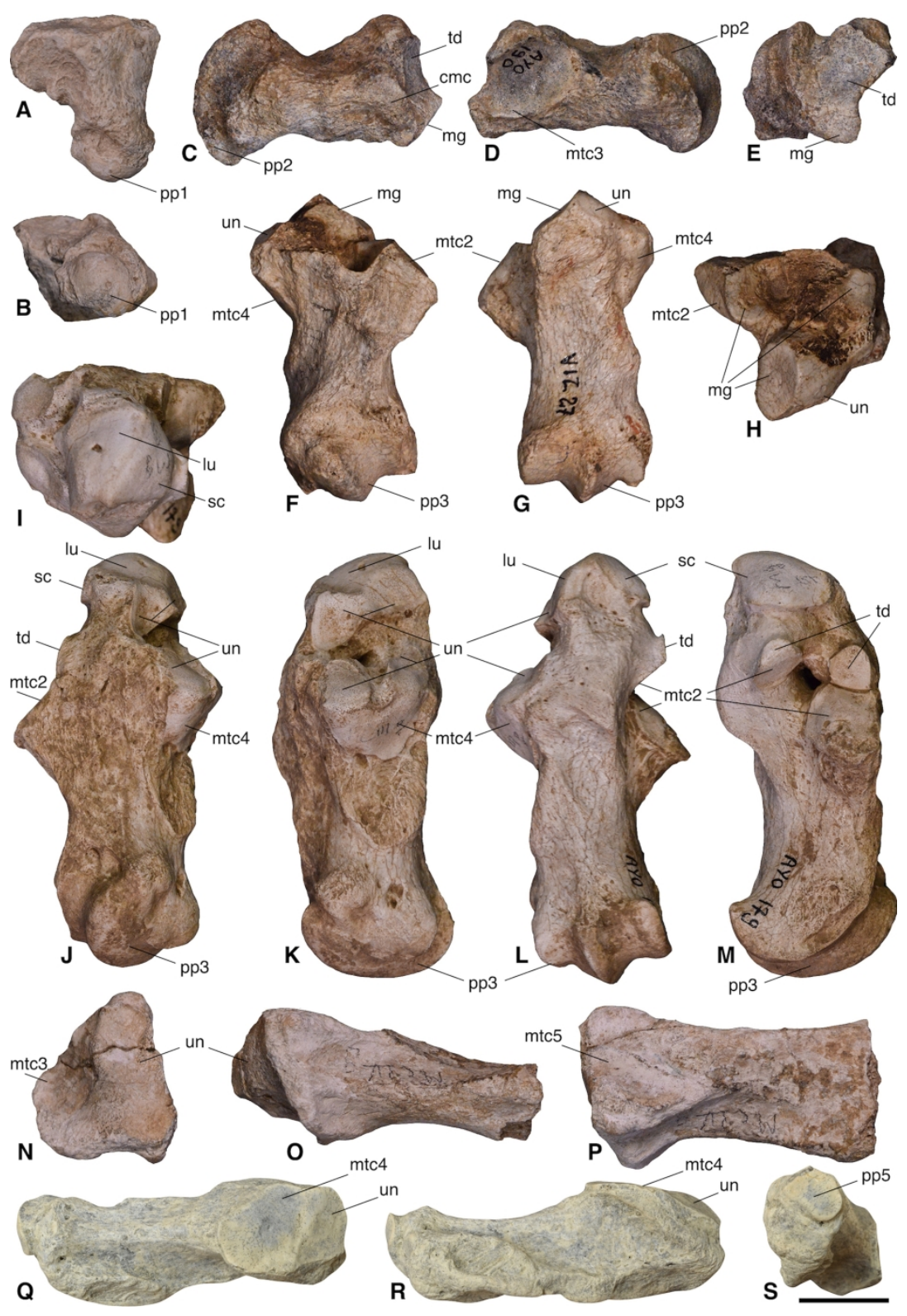

Fig. 7. Metacarpal elements of the mylodontid sloth Simomylodon uccasamamensis. A-B, right carpalmetacarpal complex (MNHN.F.VIZ32) in dorsal (A) and distal (B) views; C-E, right metacarpal II (MNHN.F.AYO190) in anterior (C), posterior (D) and proximal (E) views; F-H, right metacarpal III (MNHN.F.VIZ27) in dorsal (F), palmar (G) and proximal (H) views; I-M, left metacarpal III fused with magnum (MNHN.F.AYO179) in proximal (I), dorsal (J), posterior (K), palmar (L) and anterior (M) views; N$\mathrm{P}$, proximal fragment of left metacarpal IV (MNHN.F.VIZ33) in proximal $(\mathrm{N})$, dorsal $(\mathrm{O})$ and posterior $(\mathrm{P})$ views; Q-S, left metacarpal V (MNHN-Bol V 13367) in anterior (Q), dorsal (R) and distal (S) views. Abbreviations refer to articular facets for the indicated bones, as follows: cmc, carpal-metacarpal complex; lu, lunar; mg, magnum; mtc (2-3-4-5), metacarpal (2-3-4-5); pp (1-2-3-5), proximal phalanx (1-2-3-5); sc, scaphoid; td, trapezoid; un, unciform. Scale bar equals $2 \mathrm{~cm}$. 

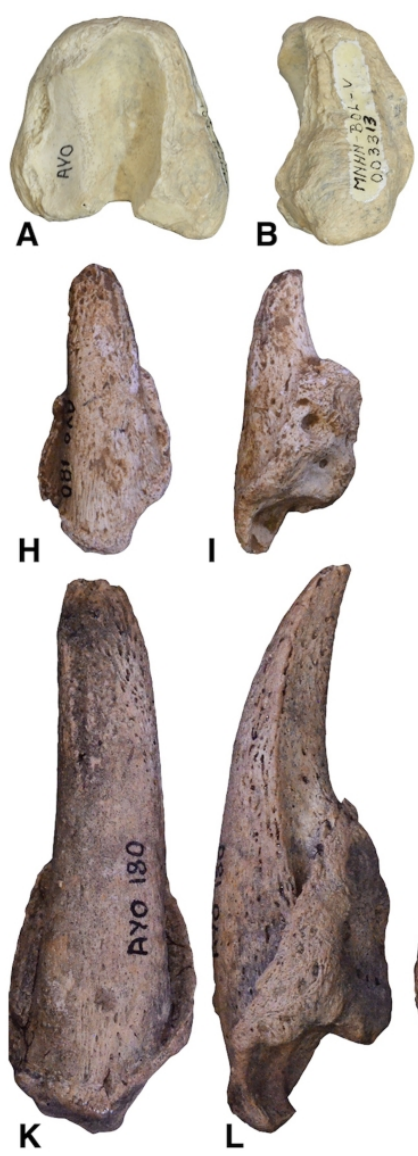
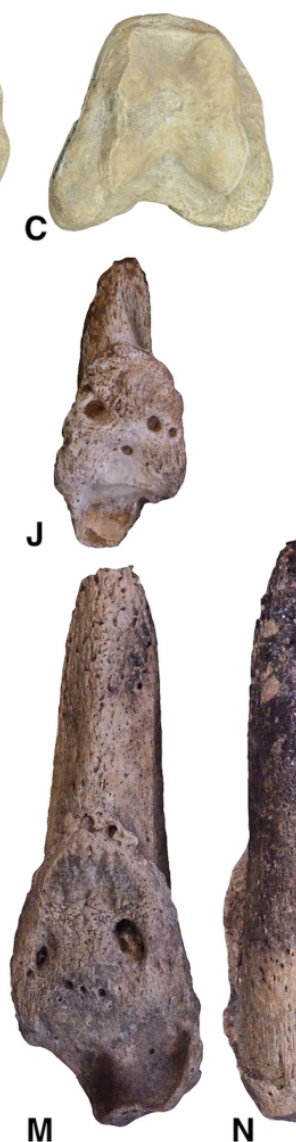
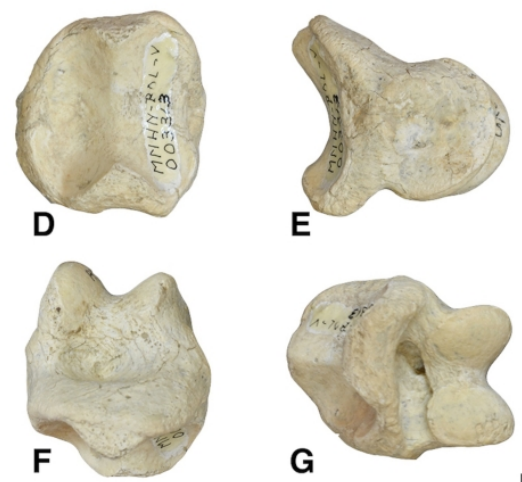

G
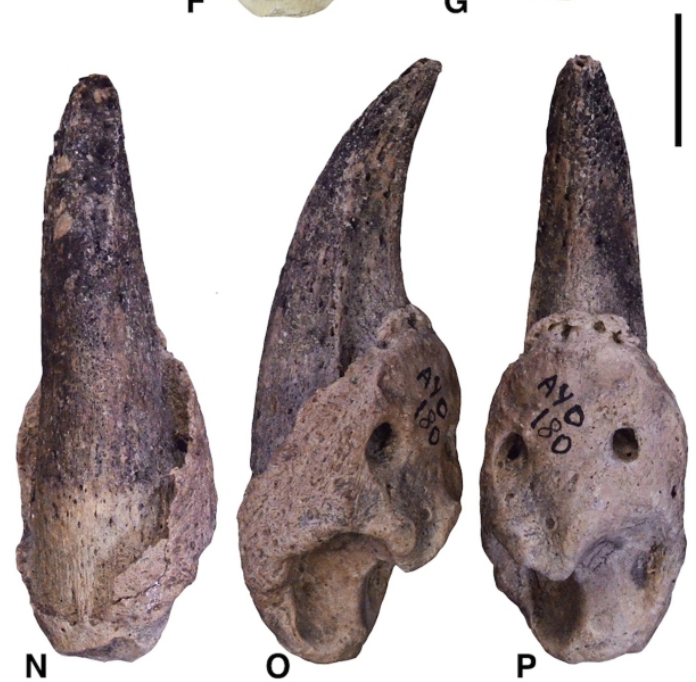

Fig. 8. Manual phalanges of the mylodontid sloth Simomylodon uccasamamensis. A-C, right proximal phalanx of third digit (MNHN-Bol V 3313) in proximal (A), lateral (B) and distal (C) views; D-G, right intermediate phalanx of third digit (MNHN-Bol $\vee 3313$ ) in proximal $(D)$, lateral $(E)$, dorsal $(F)$ and palmar (G) views; $\mathrm{H}-\mathrm{J}$, left ungual phalanx of first digit (MNHN.F.AYO180) in dorsal (H), medial (I) and palmar (J) views; K-M, left ungual phalanx of second digit (MNHN.F.AYO180) in dorsal (K), medial (L) and palmar (M) views; N-P, left ungual phalanx of third digit (MNHN.F.AYO180) in dorsal $(\mathrm{N})$, medial $(\mathrm{O})$ and palmar $(\mathrm{P})$ views. Scale bar equals $2 \mathrm{~cm}$. 


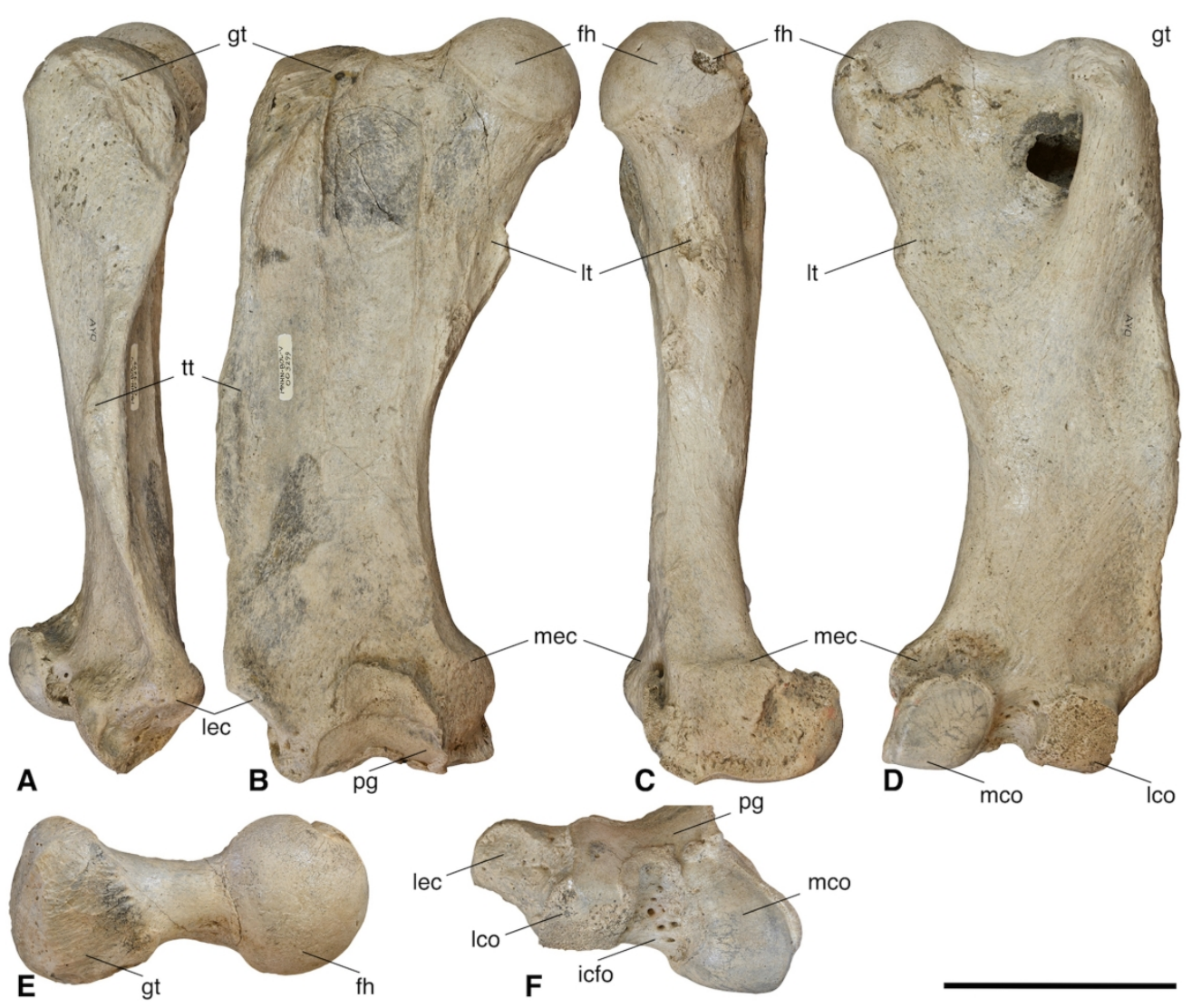

Fig. 9. Right femur of the mylodontid sloth Simomylodon uccasamamensis (MNHN-Bol V 3299) in lateral (A), anterior (B), medial (C), posterior (D), proximal (E) and distal (F) views. Abbreviations: fh, femoral head;

gt, greater trochanter; icfo, intercondylar fossa; Ico, lateral condyle; lec, lateral epicondyle; It, lesser trochanter; mco, medial condyle; mec, medial epicondyle; pg, patellar groove; tt, third trochanter. Scale bar equals $10 \mathrm{~cm}$.

$165 \times 138 \mathrm{~mm}(600 \times 600 \mathrm{DPI})$ 

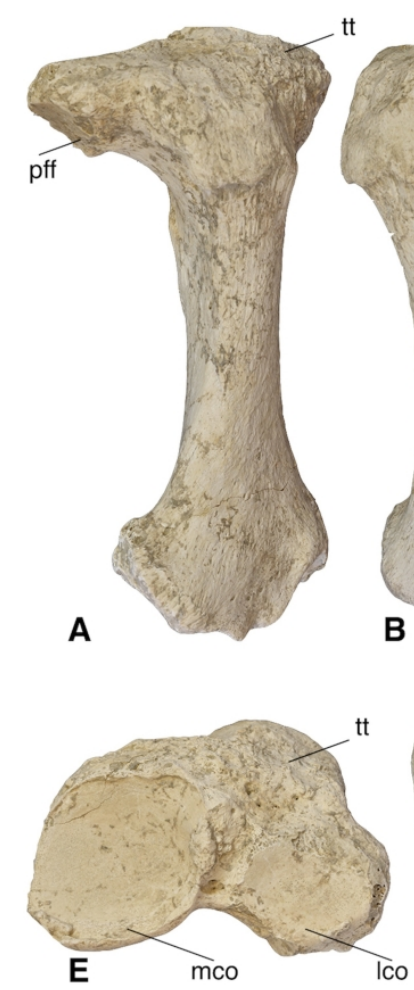

B
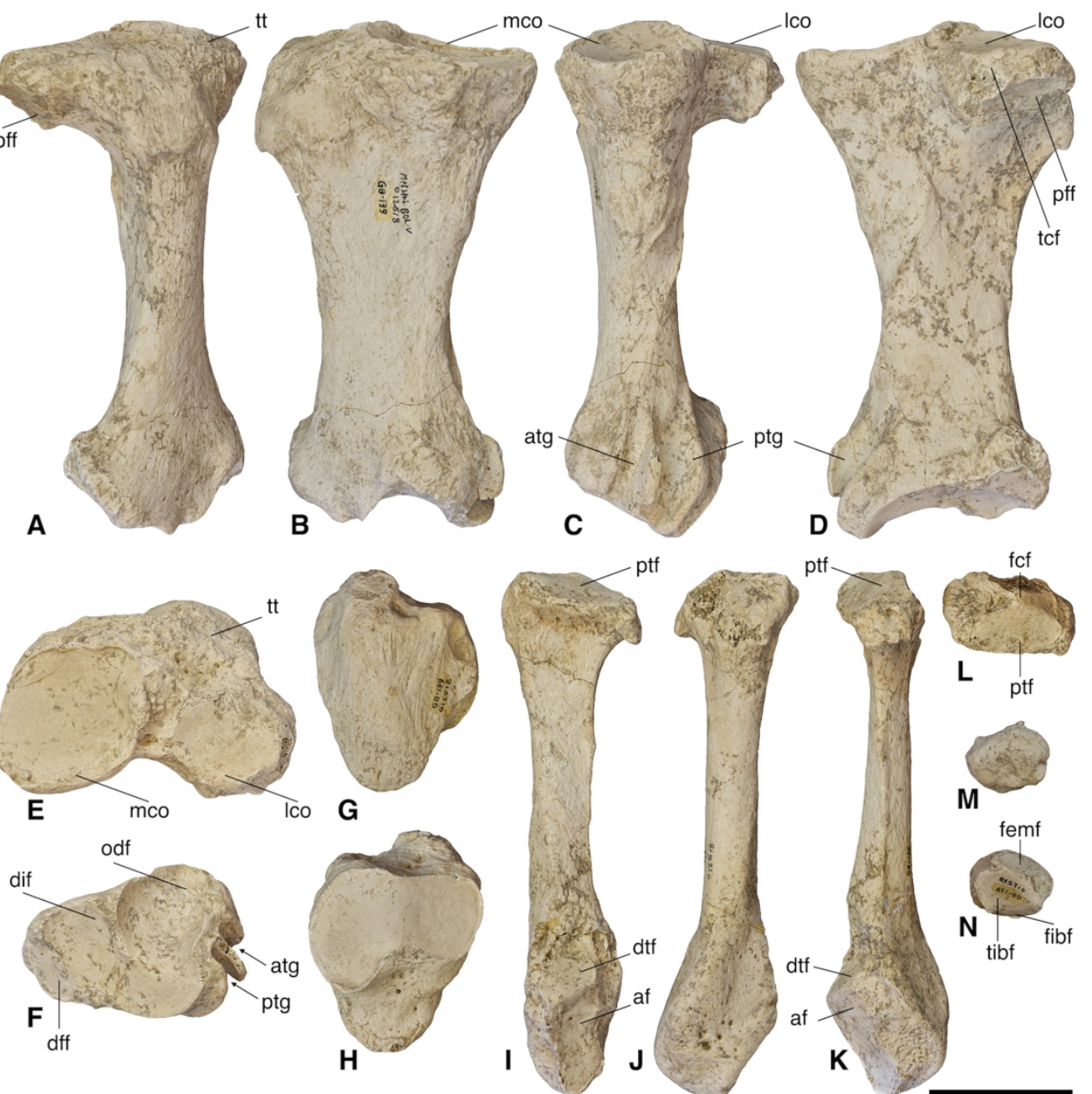

Fig. 10. Tibia, patella, fibula, and cyamella of the mylodontid sloth Simomylodon uccasamamensis (MNHNBol V 12518). A-F, right tibia in lateral (A), anterior (B), medial (C), posterior (D), proximal (E) and distal (F) views; G-H, right patella in anterior $(\mathrm{G})$ and posterior $(\mathrm{H})$ views; I-L, right fibula in medial (I), lateral (J), posterior (K) and proximal (L) views; M-N, right cyamella in lateral $(\mathrm{M})$ and articular $(\mathrm{N})$ views.

Abbreviations: af, astragalar facet; atg, anterior tibial groove (for $\mathrm{m}$. tibialis caudalis); dff, distal fibular facet; dif, discoid process facet; dtf, distal tibial facet; fcf, fibular cyamella facet; femf, femoral facet; fibf, fibular facet; Ico, lateral condyle; mco, medial condyle; odf, odontoid process facet; pff, proximal fibular facet; ptf, proximal tibial facet; ptg, posterior tibial groove; tcf, tibial cyamella facet; tibf, tibial facet; tt, tibial tuberosity. Scale bar equals $5 \mathrm{~cm}$.

$$
165 \times 166 \mathrm{~mm}(600 \times 600 \text { DPI) }
$$



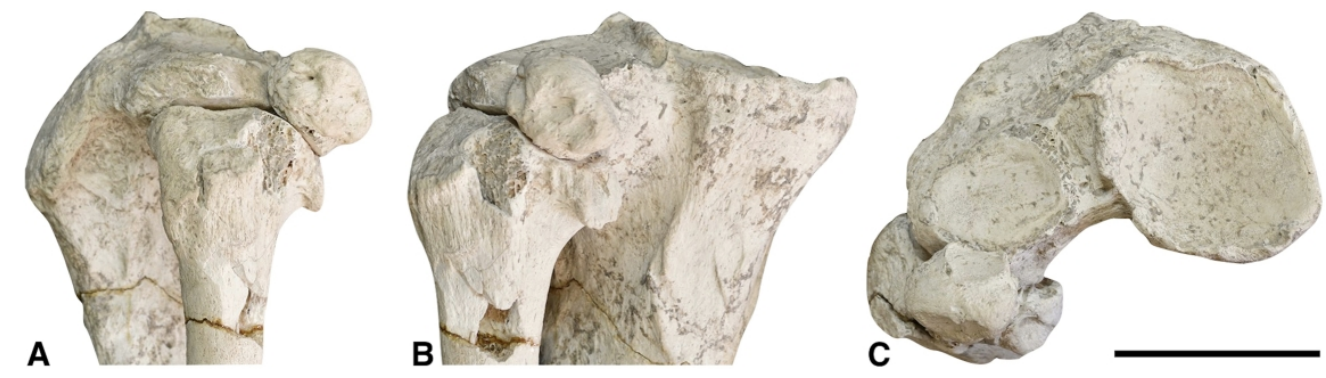

Fig. 11. Left tibia, fibula, and cyamella of the mylodontid sloth Simomylodon uccasamamensis (MNHN-Bol V 12518 ) showing connections among the three elements, in lateral (A), posterior (B) and proximal (C) views. Scale bar equals $5 \mathrm{~cm}$. $165 \times 46 \mathrm{~mm}(600 \times 600 \mathrm{DPI})$ 


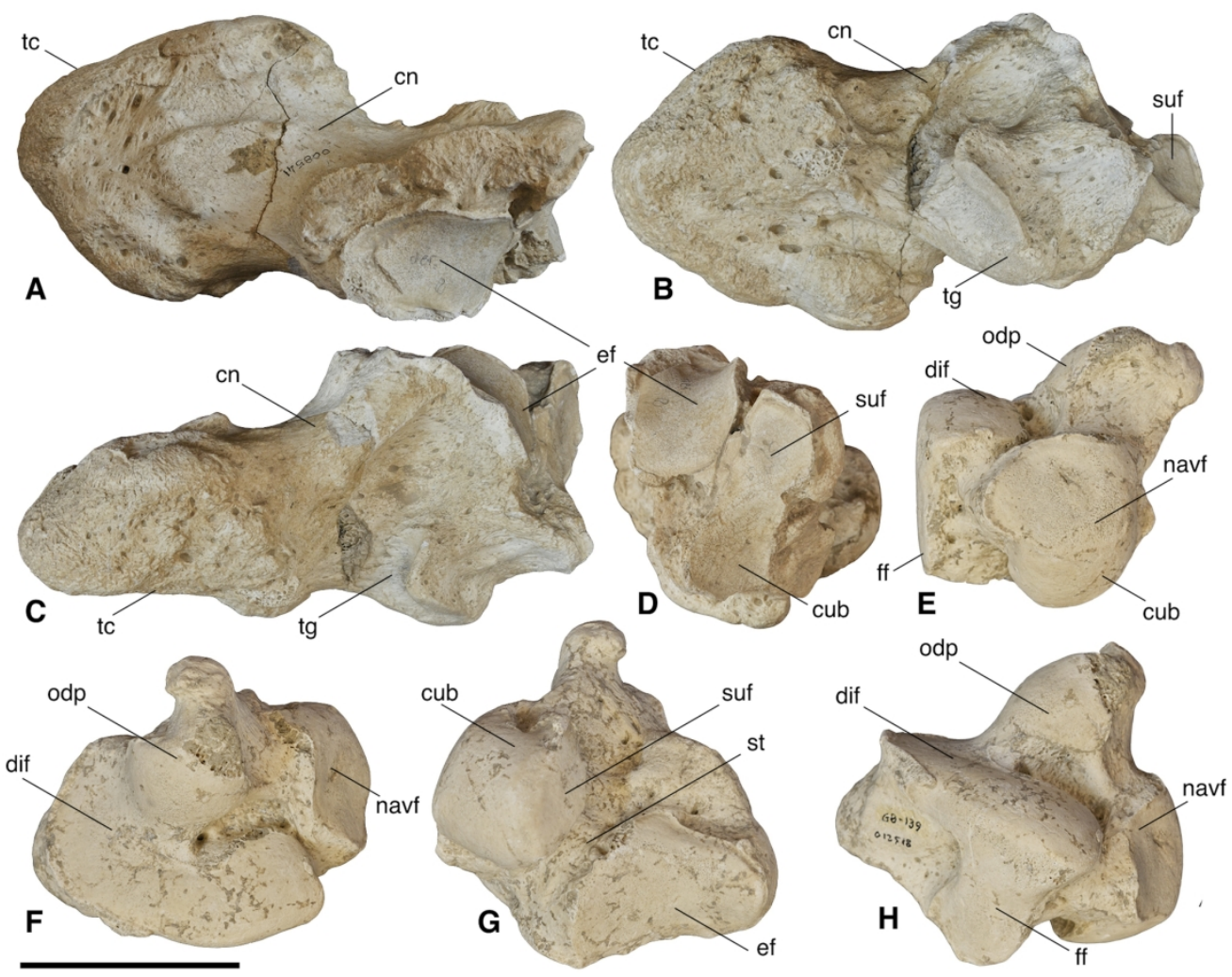

Fig. 12. Calcaneum and astragalus of the mylodontid sloth Simomylodon uccasamamensis. A-D, right calcaneum (MNHN-Bol V 8541) in proximal (A), distal (B), lateral (C) and anterior (D) views; $\mathrm{E}-\mathrm{H}$, right astragalus (MNHN-Bol V 12518) in anterior (E), proximal $(F)$, medial $(G)$ and lateral $(H)$ views.

Abbreviations: cn, calcaneal neck; cub, cuboid facet; dif, discoid facet; ef, ectal facet; ff, fibular facet, navf, navicular facet; odp, odontoid process; st, sulcus tali; suf, sustentacular facet; tc, tuber calcis; tg, tendinous groove. Scale bar equals $5 \mathrm{~cm}$.

[Suggested size: full page width]

$165 \times 130 \mathrm{~mm}(300 \times 300 \mathrm{DPI})$ 

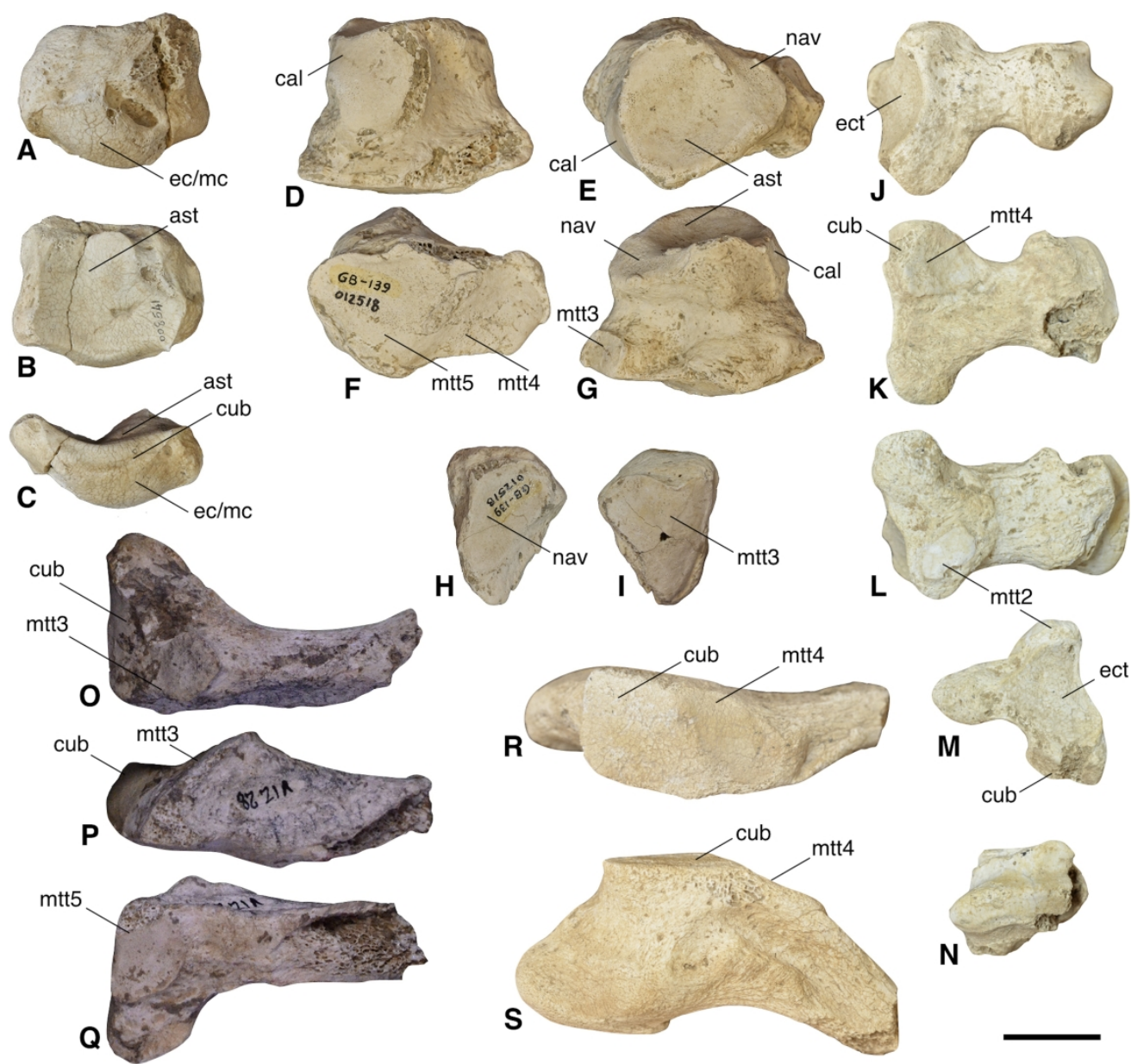

L
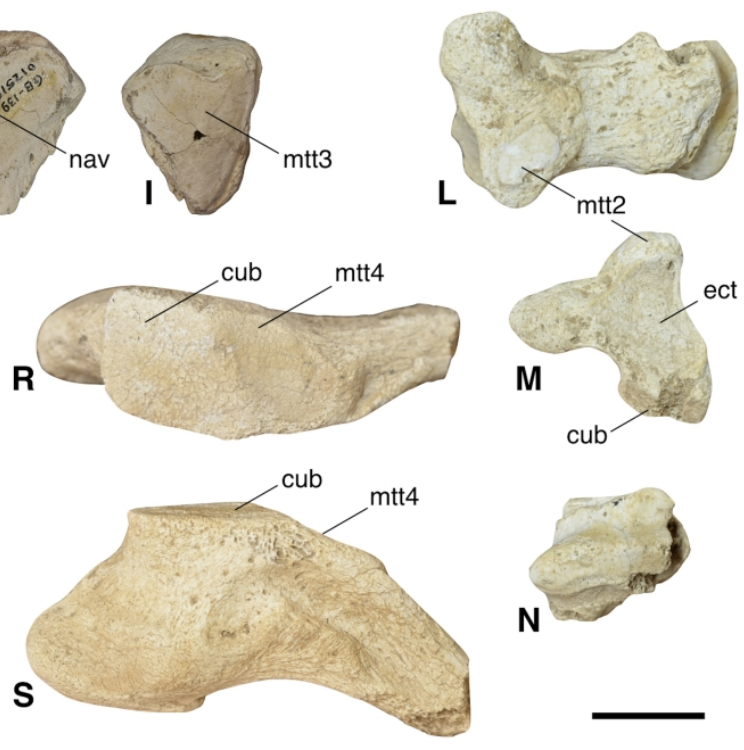

Fig. 13. Tarsal and metatarsal elements of the mylodontid sloth Simomylodon uccasamamensis. A-C, right navicular (MNHN-Bol V 8541) in distal (A), proximal (B) and lateral (C) views; D-G, right cuboid (MNHN-Bol $\checkmark$ 12518) in dorsal (D), proximal (E), distal $(F)$ and palmar (G) views; H-I, right ectocuneiform (MNHN-Bol V 12518) in proximal (H) and distal (I) views; J-N, right metatarsal III (MNHN-Bol V 13495) in dorsal (J), lateral $(\mathrm{K})$, medial $(\mathrm{L})$, proximal $(\mathrm{M})$ and distal $(\mathrm{N})$ views; $\mathrm{O}-\mathrm{Q}$, proximal fragment of right metatarsal IV (MNHN.F.VIZ28) in proximal (O), lateral (P) and distal (Q) views; R-S, fragment of metatarsal V (MNHN-Bol

$\checkmark 13450$ ) in proximal (R) and lateral (S) views. Abbreviations refer to articular facets for the indicated bones, as follows: ast, astragalus, cal, calcaneum; cub, cuboid; ec/mc, ectocuneiform and mesocuneiform; ect, ectocuneiform; mtt (2-3-4-5), metatarsal (2-3-4-5); nav, navicular. Scale bar equals $2 \mathrm{~cm}$. 


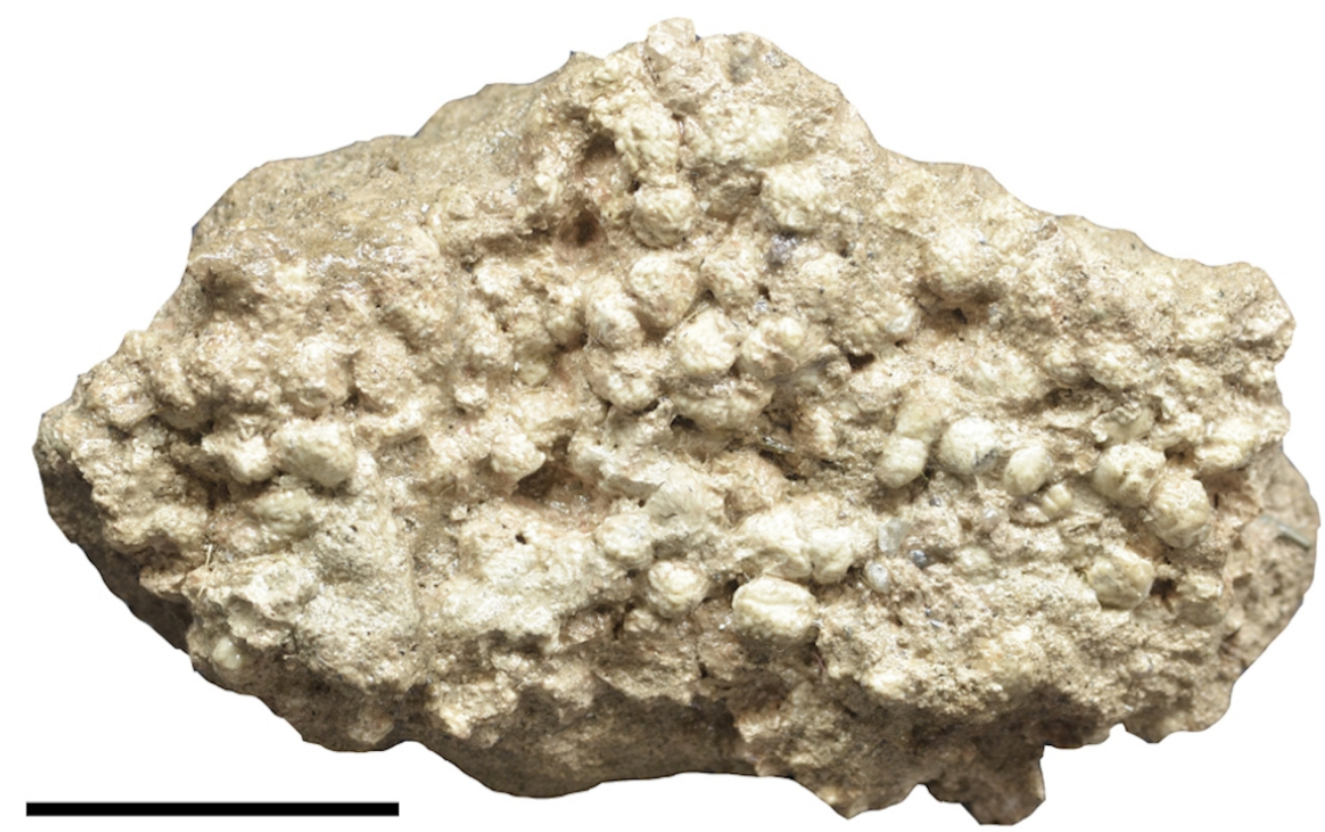

Fig. 14. Dermal ossicles of the mylodontid sloth Simomylodon uccasamamensis (MNHN-Bol V 3726) from the early Pliocene of Casira, Bolivia. Scale bar equals $2 \mathrm{~cm}$.

$80 \times 51 \mathrm{~mm}(600 \times 600 \mathrm{DPI})$ 